\title{
Bank of England Interest Rate Announcements and the Foreign Exchange Market*
}

\author{
Michael Melvin, ${ }^{\mathrm{a}}$ Christian Saborowski, ${ }^{\mathrm{b}, \mathrm{c}}$ Michael Sager, ${ }^{\mathrm{c}, \mathrm{e}}$ \\ and Mark P. Taylor ${ }^{d, f}$ \\ ${ }^{\text {a BlackRock }}$ \\ ${ }^{\mathrm{b}}$ World Bank \\ ${ }^{\mathrm{c}}$ Department of Economics, University of Warwick \\ ${ }^{\mathrm{d}}$ Warwick Business School \\ ${ }^{\mathrm{e}}$ Wellington Management \\ ${ }^{\mathrm{f}}$ Centre for Economic Policy Research
}

\begin{abstract}
Since 1997, the Bank of England Monetary Policy Committee (MPC) has met monthly to set the UK policy interest rate. Using a Markov-switching framework that incorporates endogenous transition probabilities, we examine intraday, five-minute return data for evidence of systematic patterns in exchange rate movements on MPC policy announcement days. We find evidence for non-linear regime switching between a high-volatility, informed trading state and a low-volatility, liquidity trading state. MPC surprise announcements are shown to significantly affect the probability that the market enters and remains within the informed trading regime, with some limited evidence of market positioning just prior to the announcement.

JEL Codes: E42, E44, F31.
\end{abstract}

\section{Introduction}

The Bank of England (BoE) was granted operational independence to set its key interest rate in May 1997, with the goal of implementing

${ }^{*}$ We are grateful to two anonymous referees for helpful and constructive comments on an earlier draft of this paper, the editor, Frank Smets, Charles Goodhart, Richard Meese, Carol Osler, and seminar participants at the London School of Economics, the University of Warwick, and the 2008 Global Conference on Business and Finance, held in San Jose, Costa Rica. Responsibility for any remaining omissions or errors remains with the authors. Christian Saborowski acknowledges financial support from the European Commission Marie Curie Fellowships. Corresponding author (Taylor): mark.taylor@wbs.ac.uk. 
policy consistent with stable inflation and economic growth. ${ }^{1}$ Interest rate decisions are made by the Bank's Monetary Policy Committee (MPC), which meets for two days each month - as well as an additional pre-meeting briefing day - and issues a statement regarding interest rate decisions at noon on the second meeting day. This framework allows a natural laboratory setting for examining the impact of monetary policy decisions around a known time and date. Since market participants know that interest rate announcements arrive at noon on the second meeting day, there may be positioning prior to the announcement and news effects after the announcement that result in systematic differences in the behavior of financial market variables on MPC meeting days compared with other, non-MPC days. In this paper, we concentrate on the pattern of exchange rate volatility surrounding the MPC's interest rate decisions as well as the role played by the surprise content of these announcements.

Although activities directly related to each MPC meeting are spread over three different days, our empirical analysis will focus upon the second MPC meeting day, when the policy decision is made and announced. We use high-frequency, intraday data and a Markov-switching econometric model where exchange rate returns switch between a high-volatility, informed trading state and a lowvolatility, uninformed or liquidity trading state. This framework allows for a characterization of macroeconomic news effects on the foreign exchange market that differs from the traditional approach. Thus, we hypothesize that macroeconomic news does not simply affect the market as shocks to otherwise continuous processes, but instead may change, temporarily, the entire data-generating process of exchange rates. One reason is that "hot-potato" trades are likely to dominate market turnover to an unusual degree around news events as individual dealers adjust inventory and offload onto others, effectively generating a multiplier effect on trades (Lyons 1996).

An econometric specification that allows for regime switches therefore appears appropriate, particularly as it facilitates a plausible interpretation of observed non-linearities. Moreover, and in contrast to the deterministic models typically employed in similar

\footnotetext{
${ }^{1}$ From the creation of the MPC until July 2006, policy decisions were framed in terms of the repurchase, or repo, rate and after that date in terms of the Bank rate. We use the two names interchangeably.
} 
analyses, we allow for a probabilistic and thus flexible characterization of the data. In particular, by modeling switching probabilities endogenously, our approach allows the probability of regime switching to vary during MPC meeting days. Given the notoriously capricious nature of financial markets, our approach therefore provides an interesting alternative perspective on the impact of news effects on asset prices. This is the first important contribution of our research to the existing empirical literature. The second contribution is the size of our data set-28,556 high-frequency observations spanning ten years - which to the best of our knowledge is far longer than employed by any existing study and is important in ensuring that our results are robust.

Adopting this approach, we find evidence for non-linear regime switching between a high-volatility, informed trading state and a low-volatility, liquidity trading state. MPC surprise announcements are shown to significantly affect the probability that the market enters and remains within the informed trading regime, with some limited evidence of market positioning just prior to the policy announcement.

The next section provides a brief review of the literature on the impact of macroeconomic news announcements on financial markets. In section 3 we provide some background institutional details on the MPC and the UK monetary-policy-setting process. Section 4 contains a discussion of our econometric methodology and the various hypotheses to be tested. Section 5 describes our data sets and contains our main empirical findings. Finally, section 6 summarizes our conclusions and discusses directions for future research.

\section{Exchange Rate and Asset-Price Effects of Monetary Policy Announcements: A Brief Review of the Literature}

Early intraday studies of the impact of macroeconomic news effects on exchange rates - for instance, Hakkio and Pearce (1985) and Ito and Roley (1987) - report mixed results in terms of statistical significance. This may reflect the coarseness of sampling intervals, with observations of exchange rates taken at opening, noon, and closing. If news effects work themselves out within periods less than several hours, observing the market at three equally spaced points over the 
trading day will miss much of the action. The increased availability of high-frequency, intraday foreign exchange rate data considerably advanced research in this area.

High-frequency, intraday exchange rate volatility effects of news announcements were first documented by Ederington and Lee (1993, $1995,1996) .{ }^{2}$ Ederington and Lee (1993) use five-minute tick data from November 1988 to November 1991 for mark-dollar, as well as various interest rate futures, and define their variable of interest as the deviation of the absolute value of exchange or interest rate returns in a given five-minute period on day $j$ from the average return during that period across the whole sample. Ederington and Lee (1993) regress this variable on a series of dummy variables that designate the publication schedule of U.S. macroeconomic data series. They conclude in favor of a significant change in intraday exchange and interest rate volatility upon publication of various series, including the monthly employment report, producer price inflation, and trade data. They find that the standard deviation of five-minute returns immediately after publication is at least five times higher on announcement days than on non-announcement, or control, days. In addition, although the largest volatility impact occurs within one minute of publication, the standard deviation of returns remains significantly above normal for up to forty-five minutes after publication for a number of macroeconomic series.

In an extension to their original paper, Ederington and Lee (1995) perform a similar analysis using ten-second data, and conclude that the price reaction to macroeconomic news is largely completed after only forty seconds. They also find evidence of a significant change in volatility immediately ahead of key macroeconomic data releases, suggesting that market participants act to square positions in advance of key event risk. Ahn and Melvin (2007) also report evidence of switching to a high-volatility, informed trading state during U.S. Federal Reserve (Fed) policy meetings but prior to the announcement of decisions. An extensive search of public news suggests that this informed trading state cannot be explained as the response to public information, and instead is suggestive of informed

\footnotetext{
${ }^{2}$ Taylor $(1987,1989)$ provides early high-frequency studies of the foreign exchange market and finds some evidence of the impact of news on deviations from covered interest rate parity.
} 
traders taking positions in advance of the meeting conclusion based upon their expectations of the outcome. This is a theme to which we return below.

A number of other papers have also found significant evidence of policy and macroeconomic news effects upon exchange rates, as well as other asset prices. Goodhart et al. (1993) report the most persistent impact upon exchange rate volatility - four to five days - in a GARCH-M analysis of U.S. monetary policy announcements and publication of U.S. trade data. Other studies find the persistence of news effects to be more fleeting, consistent with Ederington and Lee (1993). This includes Andersen and Bollerslev (1998) in the context of a wider study of the determinants of mark-dollar volatility, and Almeida, Goodhart, and Payne (1998), who find that the volatility impact of U.S. and German macroeconomic data releases generally dissipates within fifteen minutes of publication for U.S. data releases and within approximately three hours for German releases. In addition, Almeida, Goodhart, and Payne (1998) report that relatively few German data releases have a significant impact upon exchange rate volatility, although the number does increase when the authors account for the proximity of the next Bundesbank policy meeting; the closer the meeting, the more likely was the Bundesbank to react to data surprises. Andersen et al. (2003) similarly find that relatively few German data releases exert a statistically significant effect on exchange rates - in this case, the conditional mean. Their study also considers the impact of Federal Reserve policy announcements and various U.S. macroeconomic data series, and finds in favor of a significant, asymmetric jump effect associated with both types of news; interestingly, negative U.S. data surprises often exhibit a larger impact upon exchange rates than positive surprises.

Faust et al. (2003) use intraday, daily, and monthly data from 1994 to 2001 to estimate structural vector autoregressions (SVARs), incorporating current and future U.S. and foreign short-term interest rates, and exchange rates in order to assess the effect of U.S. monetary policy shocks on other variables in the SVARs. Although the results for interest rates are mixed, the impact of policy shocks upon exchange rates using intraday data is statistically significant. In a similar vein, Harvey and Huang (2002) examine the impact of Federal Reserve open-market operations on a range of interest and exchange rates using GMM estimation and both two-minute and 
hourly returns, over the sample 1982 to 1988. They find in favor of a significant increase in intraday interest rate futures volatility associated with so-called Fed time, but against any significant, generalized increase in exchange rate return volatility.

\section{The Monetary Policy Committee}

In May 1997, the UK Chancellor of the Exchequer announced that the BoE was to be given operational responsibility for setting interest rates via the newly created MPC. The MPC was to focus on ensuring that inflation was in line with the government-set target of 2.5 percent for the Retail Prices Index excluding mortgage interest payments "within a reasonable time period without creating undue instability in the economy." Although not made explicit, this language was widely interpreted as indicating a policy horizon of two years. The policy goal was subsequently changed to 2.0 percent in December 2003, and is now defined in terms of the harmonized consumer price index. ${ }^{3}$ Conditional on achieving its inflation target, the MPC can also address fluctuations in economic growth and employment.

The MPC meets monthly, normally on the Wednesday and Thursday following the first Monday of each month. Meeting dates for each year are made available at the end of the previous year. ${ }^{4}$ The timetable for a representative meeting is given in figure 1. On the Friday morning prior to each meeting, the Committee receives a briefing from senior BoE staff on important news and data trends. The monthly MPC meeting typically begins at 15:00 on the following Wednesday afternoon (that is, the first meeting day) with a review of the state of the UK and world economy. The BoE Chief Economist starts the meeting with a short summary of any major events since the Friday briefing. On Thursday morning (the second meeting day), the MPC reconvenes and the Governor begins with a summary of the major issues. Members are then invited to state

\footnotetext{
${ }^{3}$ The UK government retains responsibility for establishing the goal of monetary policy. The inflation target is reconfirmed in the government's annual budget statement. For institutional background on the MPC and the UK monetary policy process, see Bean (2001) and www.bankofengland.co.uk/monetarypolicy/ framework.htm.

${ }^{4}$ These are published at www.bankofengland.co.uk.
} 


\section{Figure 1. Timeline for a Representative Monetary Policy Committee Meeting}

Friday

Monday/Tuesday

Wednesday

Thursday

\begin{tabular}{|l|l|l|l|}
\hline $\begin{array}{l}\text { Half-day pre- } \\
\text { MPC meeting } \\
\text { for briefing } \\
\text { held in } \\
\text { morning. }\end{array}$ & $\begin{array}{l}\text { Staff provides } \\
\text { additional } \\
\text { information } \\
\text { requested by } \\
\text { Committee. }\end{array}$ & $\begin{array}{l}\text { Meeting begins in early } \\
\text { afternoon to debate key } \\
\text { issues and inflation } \\
\text { outlook. }\end{array}$ & $\begin{array}{l}\text { Meeting continues and vote } \\
\text { on interest rates taken. } \\
\text { Decision announced at noon } \\
\text { with implementation via } \\
\text { open-market operations at } \\
12: 15 \text { p.m. }\end{array}$ \\
\hline
\end{tabular}

their views on the appropriate policy action. The Deputy Governor responsible for monetary policy will usually speak first, with the Governor speaking last. Ultimately, the Governor offers a motion that he suspects will result in a majority and then calls for a vote, on the basis of a one-member, one-vote rule. Those in the minority are asked to state their preferred level of Bank rate. Lastly, the press statement is developed. If the decision is to change interest rates or follow a policy that was not expected by the market, the press statement will include the reasons for the action taken. In other cases, simply the decision is reported. This decision is announced at noon, London time, and policy is implemented with open-market operations beginning at 12:15 p.m. on the same day.

\section{Methodology}

The focus of this paper is on inference regarding movements in the dollar-sterling exchange rate around the time of the monthly MPC policy announcement, which occurs at noon on the second meeting day, as discussed above. As foreign exchange market participants know in advance when MPC decisions are announced, we examine five-minute dollar-sterling exchange rate returns for evidence of changes in market positioning during the meeting and whether such changes are driven by the news content of the policy announcement.

It is usual to think of high-frequency exchange rate data on any given day as bounded within a fairly narrow band and exhibiting first-order autocorrelation. By contrast, on MPC meeting days we may expect important news to be received by the market. We find it convincing to think of these news effects as changing, 
temporarily, the entire data-generating process of exchange ratesand other financial variables - rather than simply introducing a onetime shock to an otherwise continuous process. Intuitively, so-called "hot-potato" trades are likely to dominate the market to an unusual degree in the immediate aftermath of the news as dealers adjust their inventory and offload onto other dealers, effectively generating a multiplier effect on trades (Lyons 1996).

An econometric specification allowing for regime switches is therefore appropriate. We adopt the Markov-switching framework associated with Hamilton (1990, 1994). An important advantage of this framework is that it facilitates a plausible interpretation of observed non-linearities and allows, in our application, for probabilistic rather than deterministic switching between regimes. A Markov-switching first-order autoregressive model can be written as

$$
\begin{aligned}
\Delta e_{t} & =\mu\left(S_{t}\right)+\rho\left(S_{t}\right)\left[\Delta e_{t-1}-\mu\left(S_{t-1}\right)\right]+\varepsilon_{t} \\
\varepsilon_{t} & \sim N\left[0, \sigma^{2}\left(S_{t}\right)\right],
\end{aligned}
$$

where $\Delta e_{t}$ is the change in the logarithm of the exchange rate at time $t$. The mean of the exchange rate returns process, $\mu$, the autocorrelation coefficient, $\rho$, and the variance of the innovation, $\varepsilon_{t}$, are allowed to take on one of two values depending on the realization of an unobserved state variable $S_{t} \in\{1,2\}$. In our application, we assume a two-state Markov process. One of the states (say, state 2) may be thought of as reflecting the usual pattern of exchange rate returns with negative autocorrelation and a relatively small variance. This tranquil state is associated with liquidity trading when no important information arrives in the market. The other state (state 1) may be thought of as the informed trading state when volatility is high and realized returns much larger than normal (Easley and O'Hara 1992; Lyons 2001).

Thus far, our proposed methodology is similar to that employed, inter alia, in Engel and Hamilton (1990). However, we diverge from the traditional Markov approach by modeling the probability of switching from one regime to another endogenously. Denoting the transition probability of switching from regime $j$ to regime $i$ at time $t$ as $P_{t}^{i j}$ for $i, j \in\{1,2\}$, we can write the postulated functions for the transition probabilities, conditional upon information at time $t$, $I_{t}$, and the previous state, as 


$$
P_{t}^{i i}=\operatorname{Pr}\left[S_{t}=i \mid S_{t-1}=i, I_{t}\right]=\Phi\left[\alpha_{i i}+\beta_{i i}^{\prime} X_{t}\right]
$$

for $i \in\{1,2\}$, where $\Phi[]$ denotes the cumulative normal density function (in order to ensure that the probabilities lie in the unit interval) and where $X_{t} \in I_{t}$ is a vector of variables known at time $t$ which may influence the transition probability according to the vector of loadings $\beta_{i}$. Given $P_{t}^{11}$, we implicitly have $P_{t}^{21}=1-P_{t}^{11}$; similarly, given an estimate of $P_{t}^{22}$, we implicitly have $P_{t}^{12}=1-P_{t}^{22}$.

The Markov-switching framework is applied to our data set to address several questions of interest. First, can we identify endogenous regime switching? Second, are the transition probabilities driven by the news component in the policy announcements? To test if the MPC policy announcement is price-relevant public news, we incorporate various dummy variables into the explanatory variable vector $X_{t}$. These dummies are set equal to one for a certain afternoon period on the second MPC meeting day, say noon to 13:00, and to zero otherwise. Third, is there evidence of positioning during the second meeting day prior to the noon policy announcement? To address this question, we incorporate dummy variables set equal to one for various time intervals prior to noon and zero otherwise.

\section{Data and Empirical Findings ${ }^{5}$}

Our data sample spans more than a decade, running from the inception of the MPC in June 1997 through October 2007, and incorporates 126 MPC meetings. Table 1 lists the MPC meeting days in our sample and the associated interest rate decisions. We classify an MPC decision as a surprise to the market if it differs from the median expectation taken from a Bloomberg survey of market economists. ${ }^{6}$ The standard deviation of analysts' expectations is reported as a measure of forecast dispersion. Table 1 also provides

\footnotetext{
${ }^{5}$ Unless otherwise stated, all references to MPC meeting days relate to second meeting days, when the policy announcement is made.

${ }^{6}$ This survey is carried out on the Friday before each MPC meeting and asks respondents for the magnitude - if any - of the interest rate change that they expect to result from the upcoming meeting. In its current guise, the survey collates the expectations of up to sixty financial economists. Although the sample of economists is not necessarily the same from one month to the next, a core subset ensures continuity.
} 


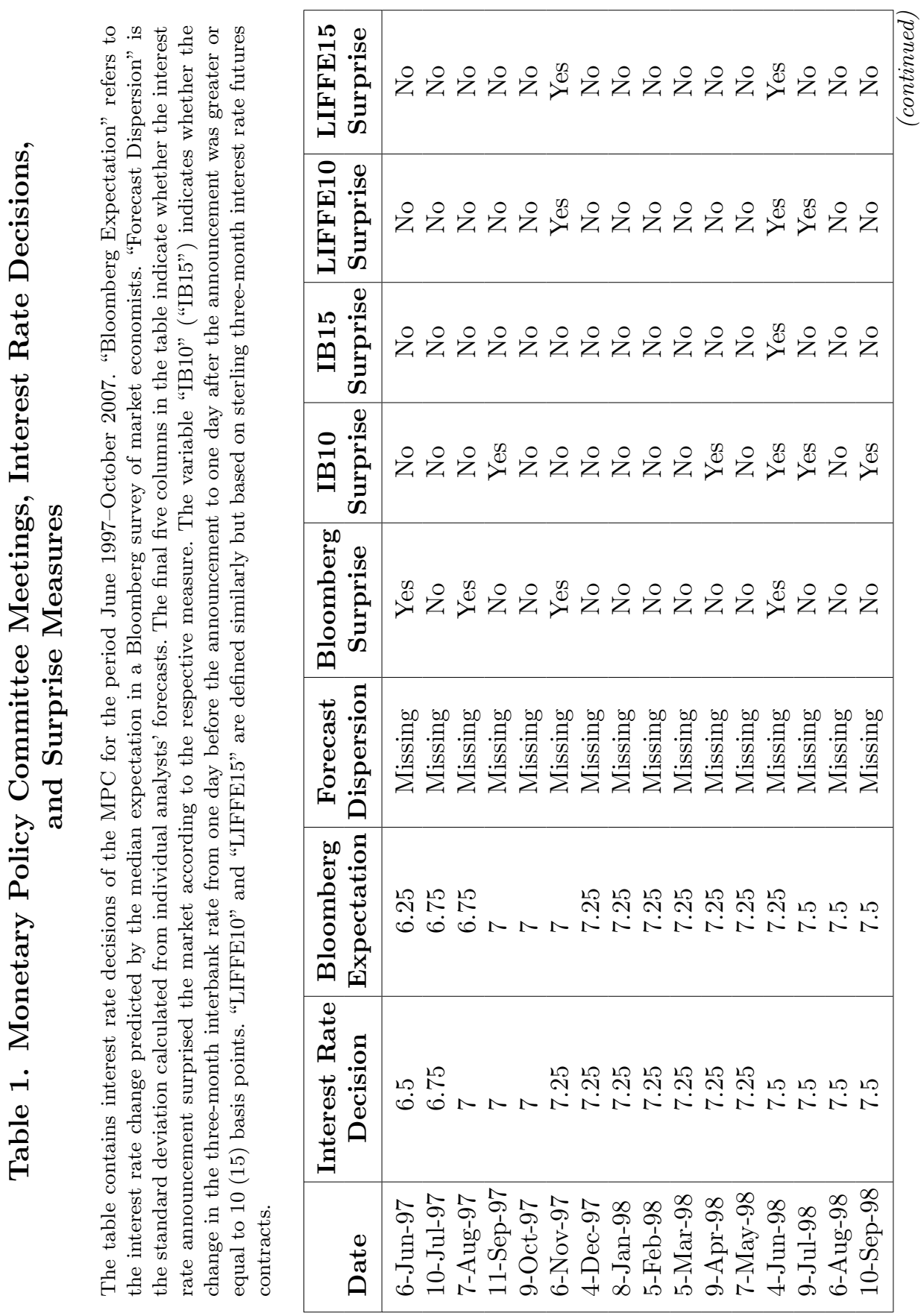




\begin{tabular}{|c|c|}
\hline 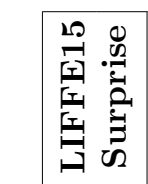 & 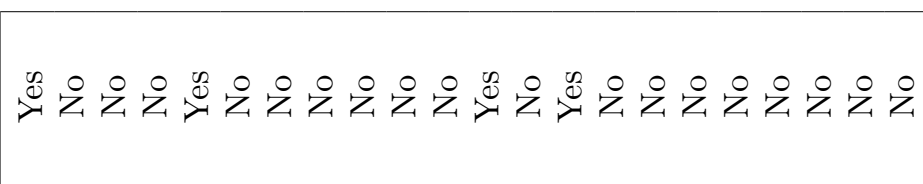 \\
\hline 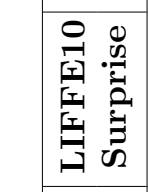 & 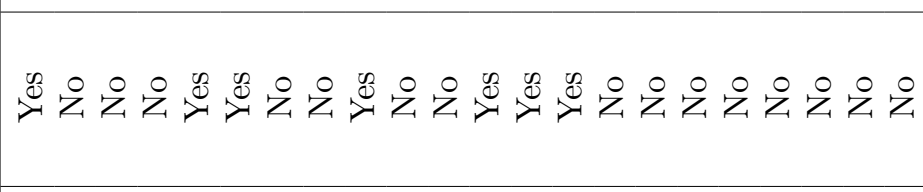 \\
\hline 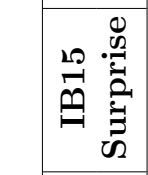 & 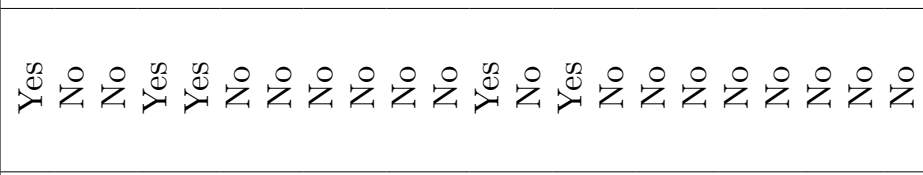 \\
\hline 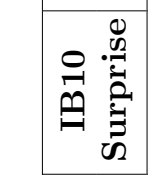 & 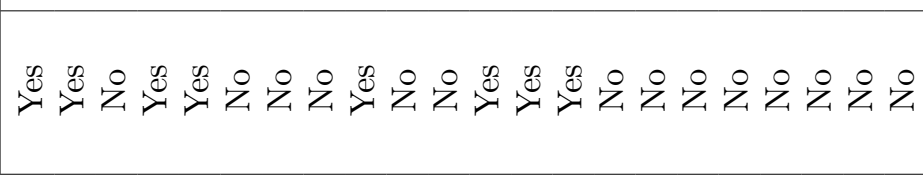 \\
\hline 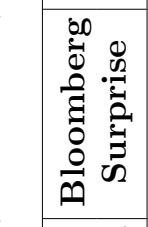 & 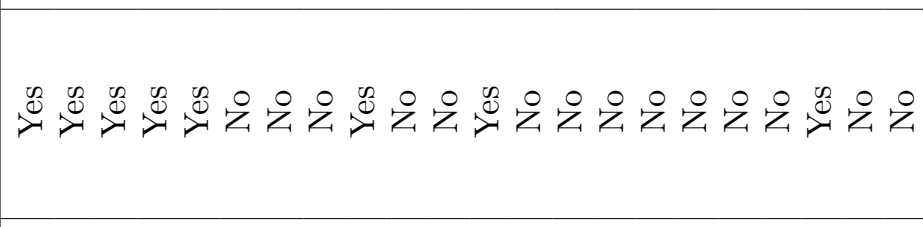 \\
\hline 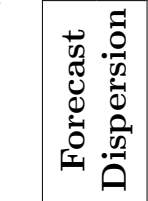 & 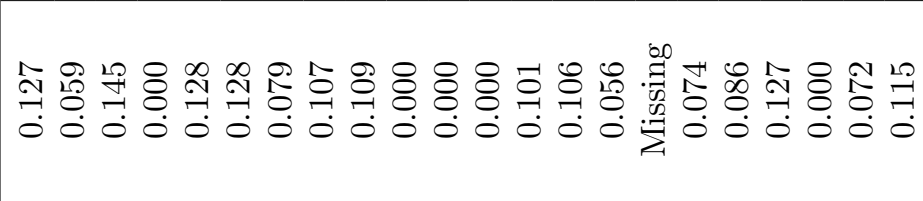 \\
\hline 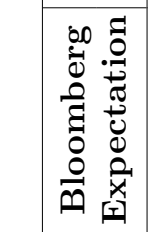 & 足 \\
\hline 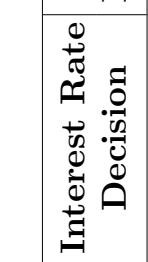 & 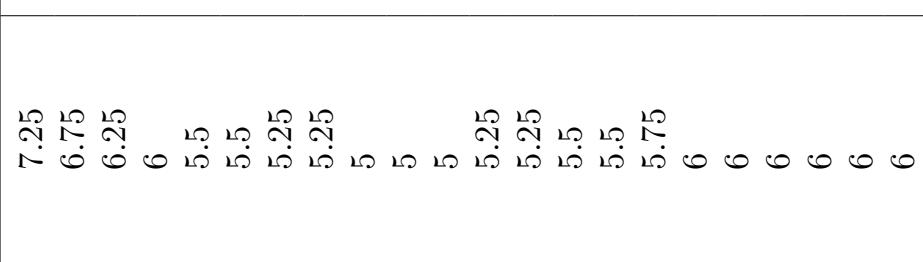 \\
\hline 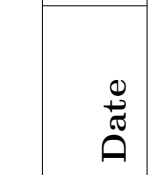 & 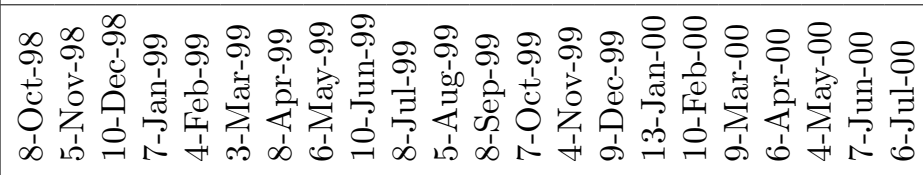 \\
\hline
\end{tabular}




\begin{tabular}{|c|c|}
\hline 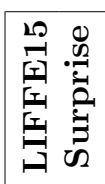 & 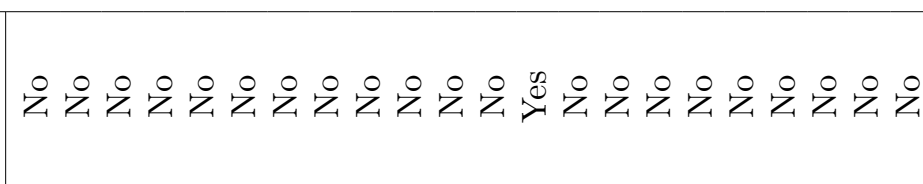 \\
\hline 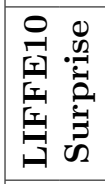 & 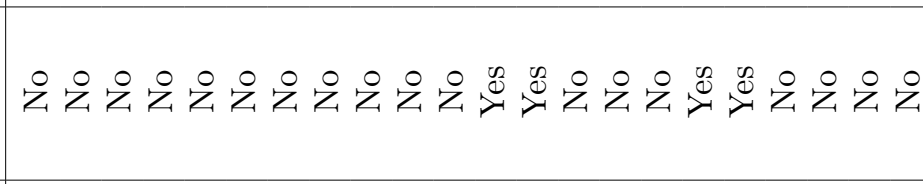 \\
\hline 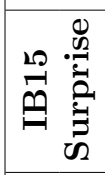 & 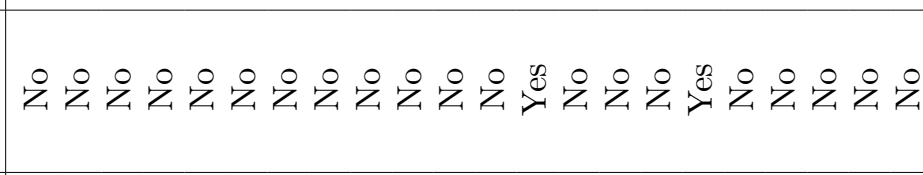 \\
\hline 里总 & 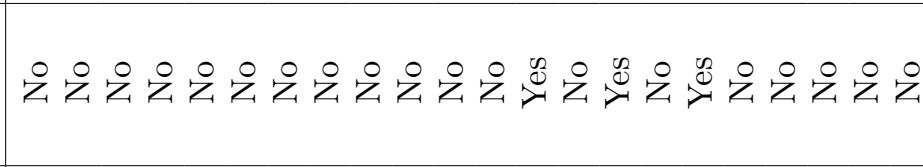 \\
\hline 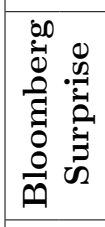 & 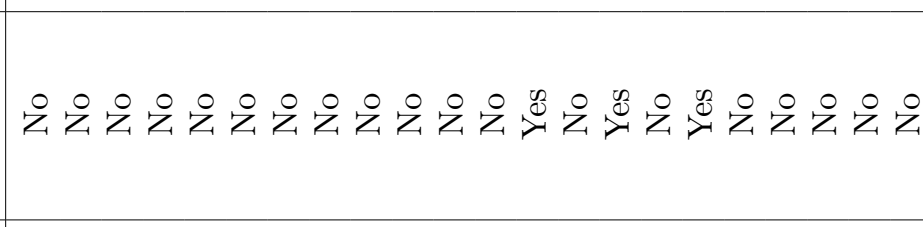 \\
\hline 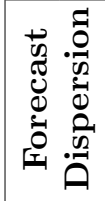 & 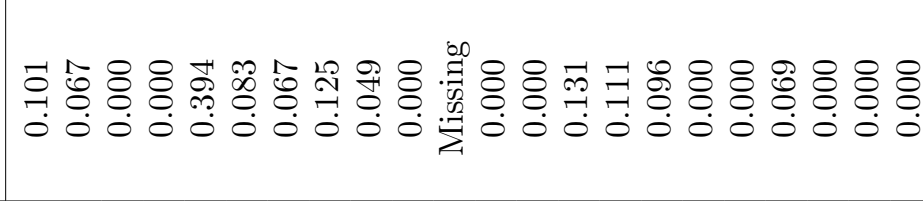 \\
\hline 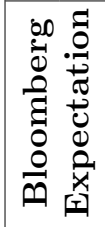 & 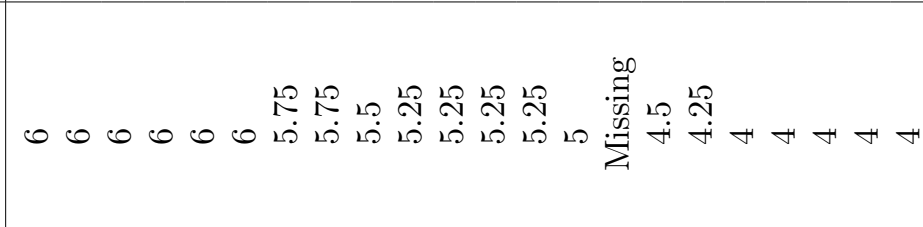 \\
\hline 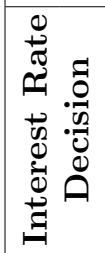 & 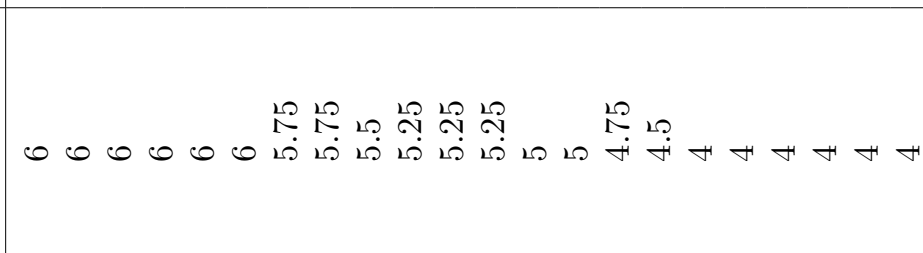 \\
\hline 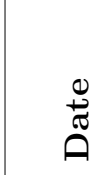 & 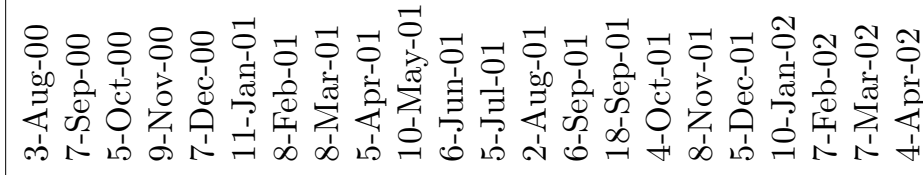 \\
\hline
\end{tabular}




\begin{tabular}{|c|c|}
\hline 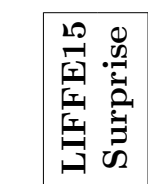 & 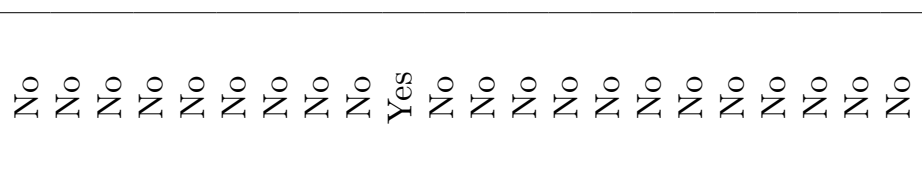 \\
\hline 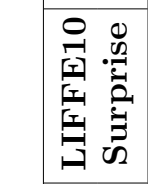 & 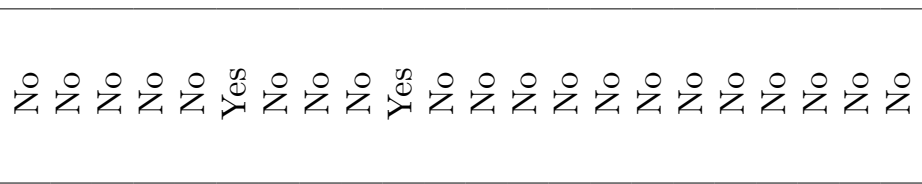 \\
\hline 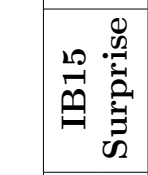 & 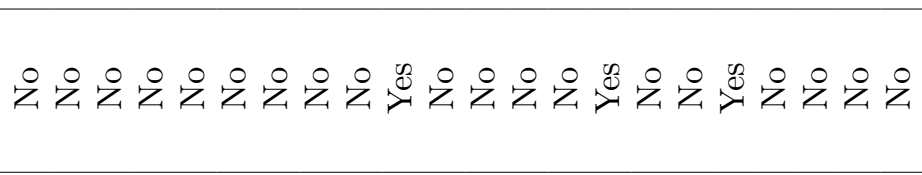 \\
\hline 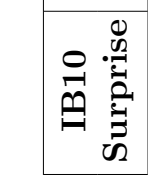 & 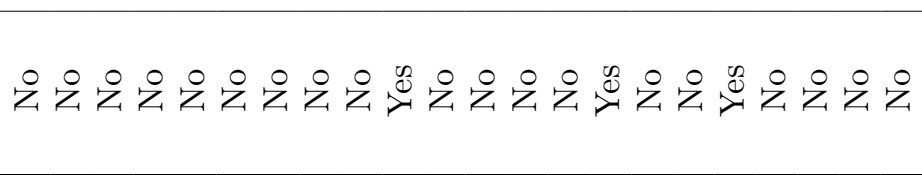 \\
\hline 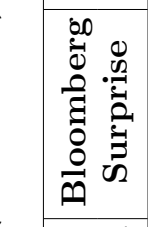 & 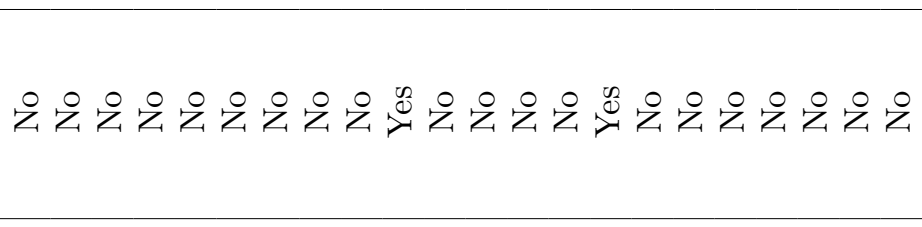 \\
\hline 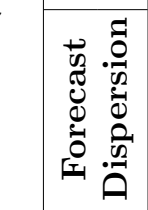 & 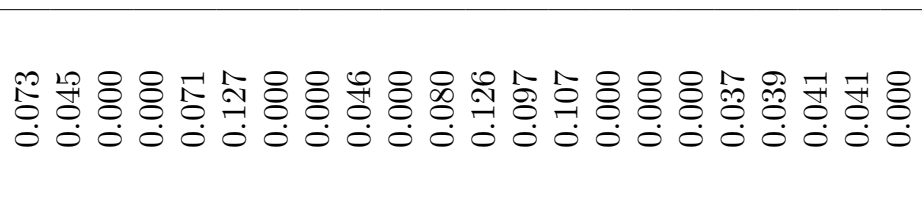 \\
\hline 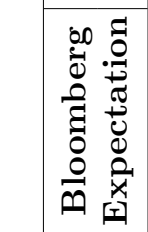 & 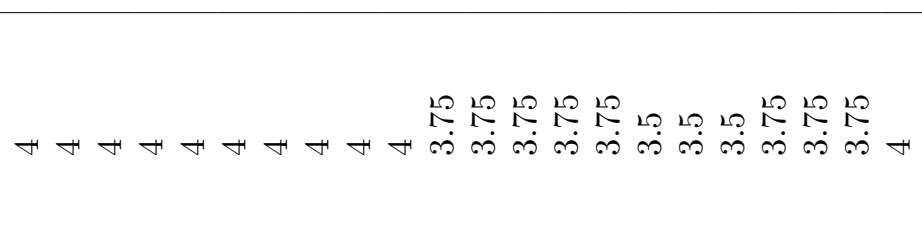 \\
\hline 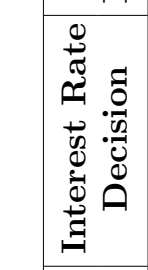 & 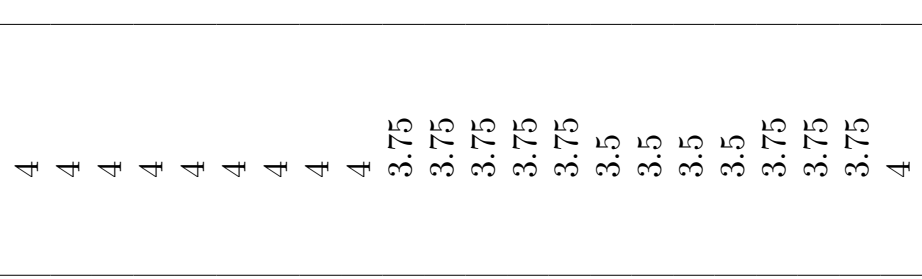 \\
\hline 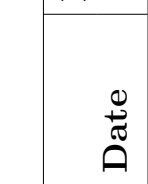 & 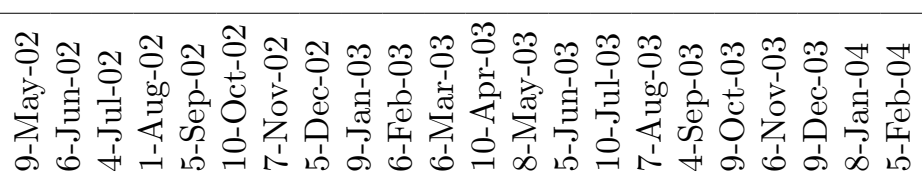 \\
\hline
\end{tabular}




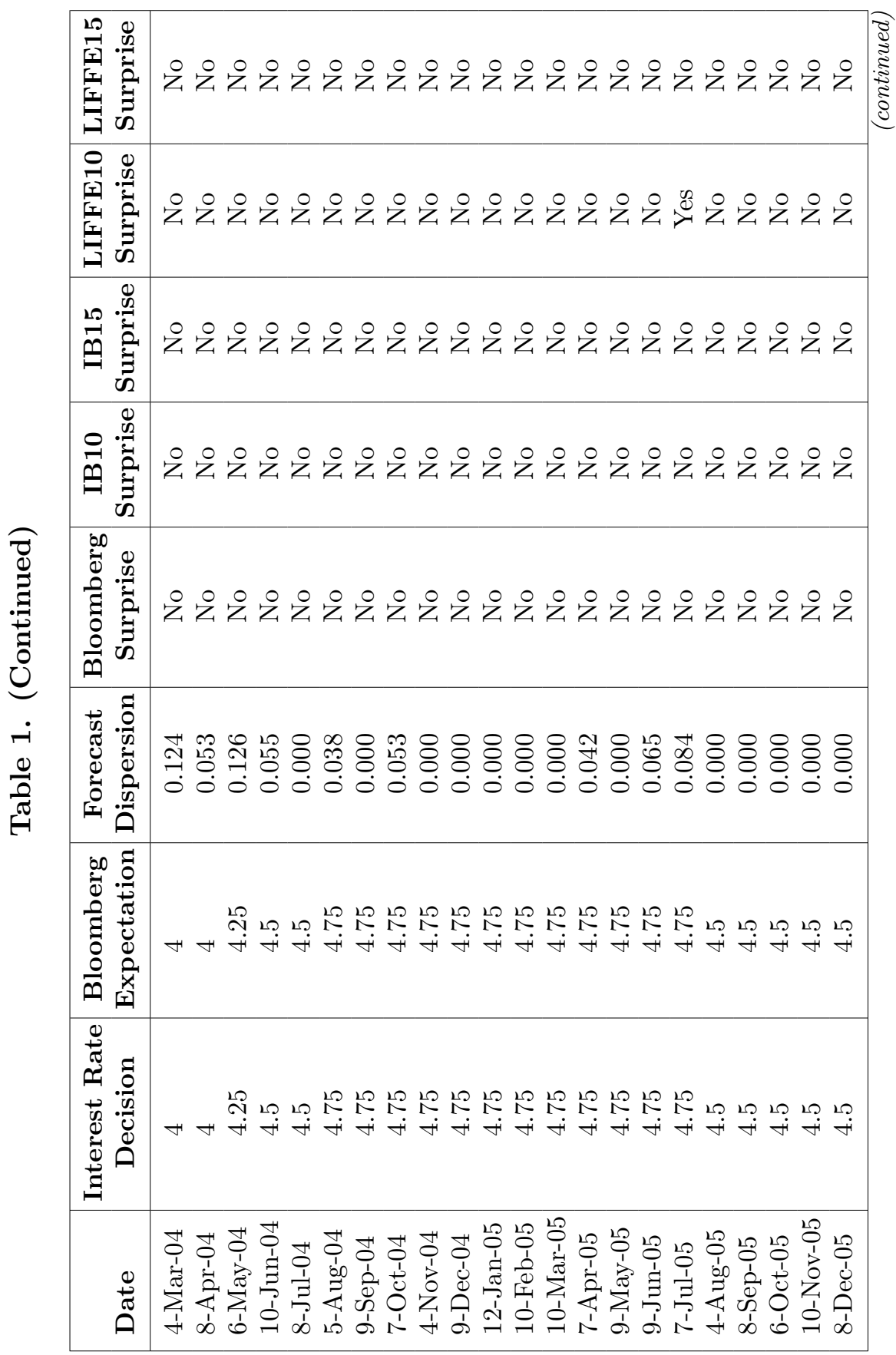




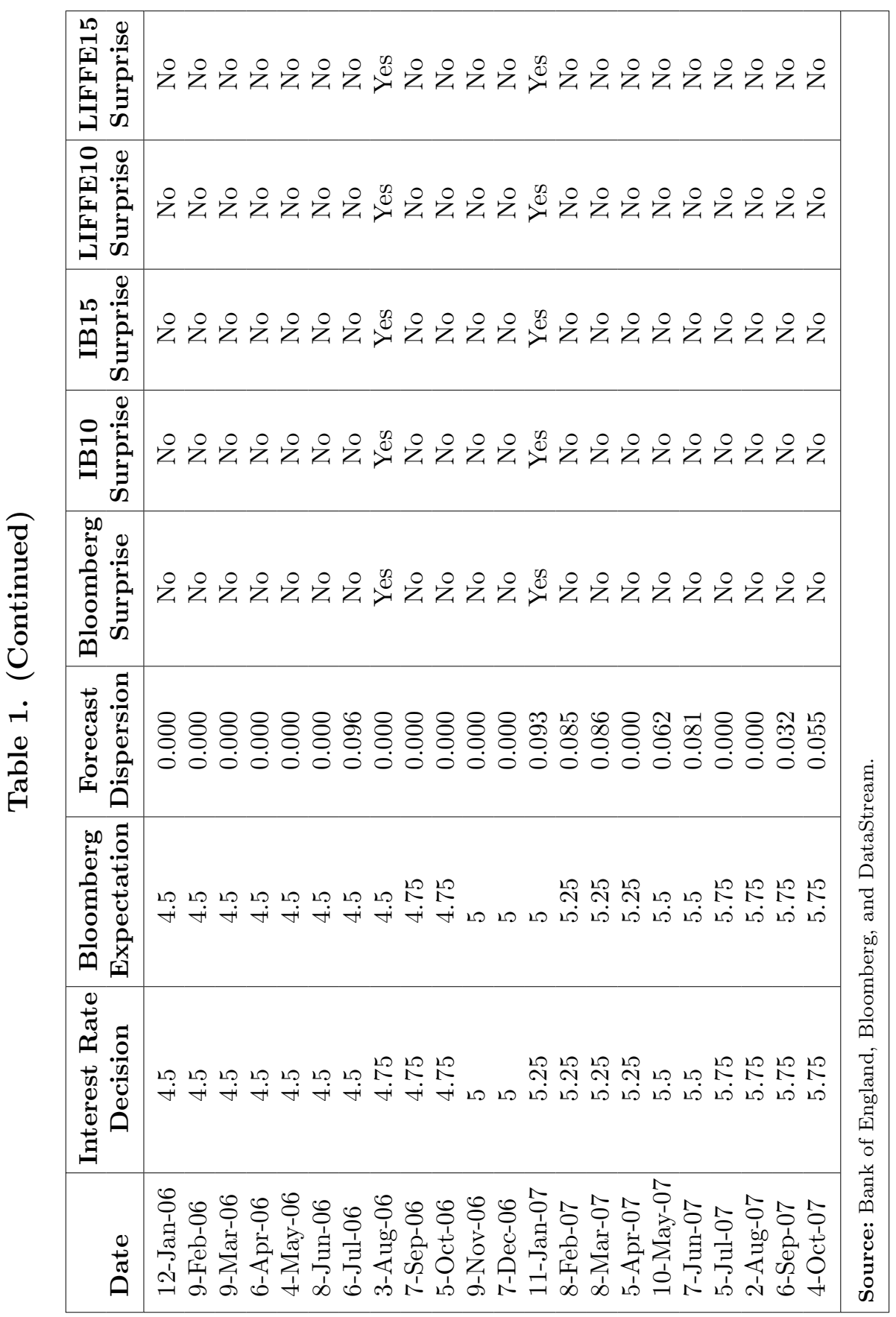


two alternative surprise measures - based on three-month interbank interest rates (IB) and three-month sterling interest rate futures contracts traded on the London International Financial Futures Exchange (LIFFE) - to be used for robustness checks. ${ }^{7}$

Table 1 suggests that the Bank of England has succeeded in achieving its goal of improving monetary policy transparency (King 2000). All measures of market expectations show a clear trend lower in the frequency of policy surprises. The Bank rate was changed on thirty-six occasions during our sample: raised at nineteen meetings and lowered at seventeen meetings. One-half of these instances were fully expected by the market, as measured by the Bloomberg survey. For the other eighteen instances, the market was either surprised that the MPC changed the policy rate or was surprised by the extent of the change. There were no instances where the market expected a change in the policy rate in the opposite direction to the change actually announced, although in May 2000 the market expected a change whereas the MPC kept the Bank rate constant. Overall, therefore, we observe nineteen policy surprises during our sample according to the Bloomberg survey. ${ }^{8}$ Consequently, we separate our sample of 126 second MPC meeting days into two parts: (i) the 107 second meeting days when the change in the policy rateincluding a change of 0 basis points - was in line with expectations (we term these "No Unexpected Change" days) and (ii) the nineteen days when the announced rate changed by an amount different to market expectations (we term these "Unexpected Change" days).

Tick data for the dollar-sterling exchange rate were obtained from a major international bank for each of our 126 MPC meeting days and a set of 126 control days, defined as the same day of the week as the MPC meeting seven days later. Insufficient exchange rate data were available for 14 out of the total of 252 days. $^{9}$

\footnotetext{
${ }^{7}$ The period $t$ policy announcement is classified as a surprise to the market if the difference between the rate in periods $t+1$ (interbank or LIFFE) and $t-1$ is greater than $10(15)$ basis points, where $t$ is the second MPC meeting day and the interest rate data are sampled daily.

${ }^{8}$ According to "IB10" ("IB15," "LIFFE10," "LIFFE15"), twenty-one (thirteen, nineteen, ten) policy surprises can be identified during the sample period.

${ }^{9}$ We also do not include the extraordinary, unscheduled meeting of September 18, 2001, and the respective control day on September 25, 2001.
} 
We sample the last quotation of each five-minute interval over the hours 7:00-17:00 London time to create a series of exchange rate returns, defined as the change in the logarithm of the five-minute observations multiplied by $10,000 .{ }^{10}$ By way of example, the 12:05 observation on any given day is the last quotation from within the interval 12:00-12:05. The data for each day are stacked in serial order to create a data set with 28,556 observations.

The Markov model represented by the set of equations (1) above is used to estimate the effect of MPC announcements on the transition probabilities. Estimation of the model is carried out using a modified version of the EM algorithm due to Diebold, Lee, and Weinbach (1994). The two states are identified by significant shifts in the mean $\mu$, the autocorrelation coefficient $\rho$, and the variance $\sigma^{2}$. Recall that state 1 is the high-variance state associated with informationbased trading and state 2 is the low-variance state associated with the normal market conditions of liquidity trading. Consistent with these definitions, the results in table 2 show that the estimated state 1 variance, $\sigma^{2}(1)$, is generally found to be about 3.5 times that of state $2, \sigma^{2}(2)$. Statistically significant negative first-order autocorrelation, a common feature of high-frequency exchange rate returns, is also apparent.

In table 2, panel A we report estimates of the (restricted) constant transition probability model, and in panel B the (unrestricted and preferred) time-varying transition probability model. The reported likelihood-ratio statistic is statistically significant and justifies our decision to estimate the transition probabilities endogenously. ${ }^{11}$ The transition probabilities estimated by the restricted model are reported in table $2 ; P^{11}$ is the probability of remaining in

\footnotetext{
${ }^{10}$ Danielsson and Payne (2002) compare one week of indicative quote data with firm quotes from an electronic FX brokerage and find that the properties of returns for each series become quite similar at a five-minute sampling frequency. At higher frequencies, the indicative quotes tend to lag firm quotes. We therefore choose five-minute sampling to ensure that our exchange rate returns are representative of market conditions. The raw data were referenced to Greenwich Mean Time (GMT), so time references were appropriately adjusted to account for British Summer Time.

${ }^{11}$ From the log-likelihood values reported in table 2 , this statistic is $-2(-73022+71082)=3880(\mathrm{p}$-value $=0.00)$. Note that the means are not significantly different from zero in the specification with constant transition probabilities. This is the only specification for which this is the case.
} 
228 International Journal of Central Banking September 2010

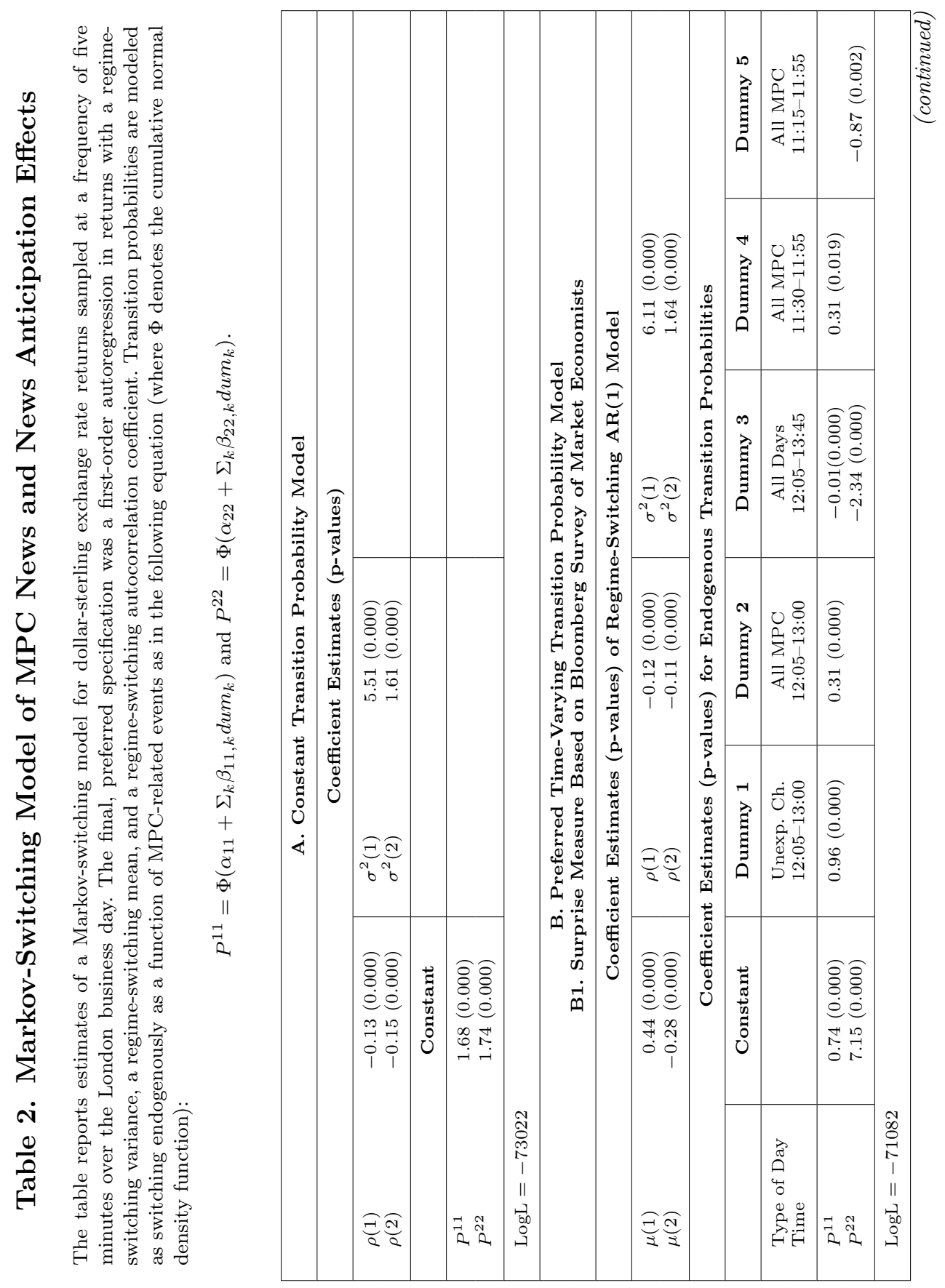




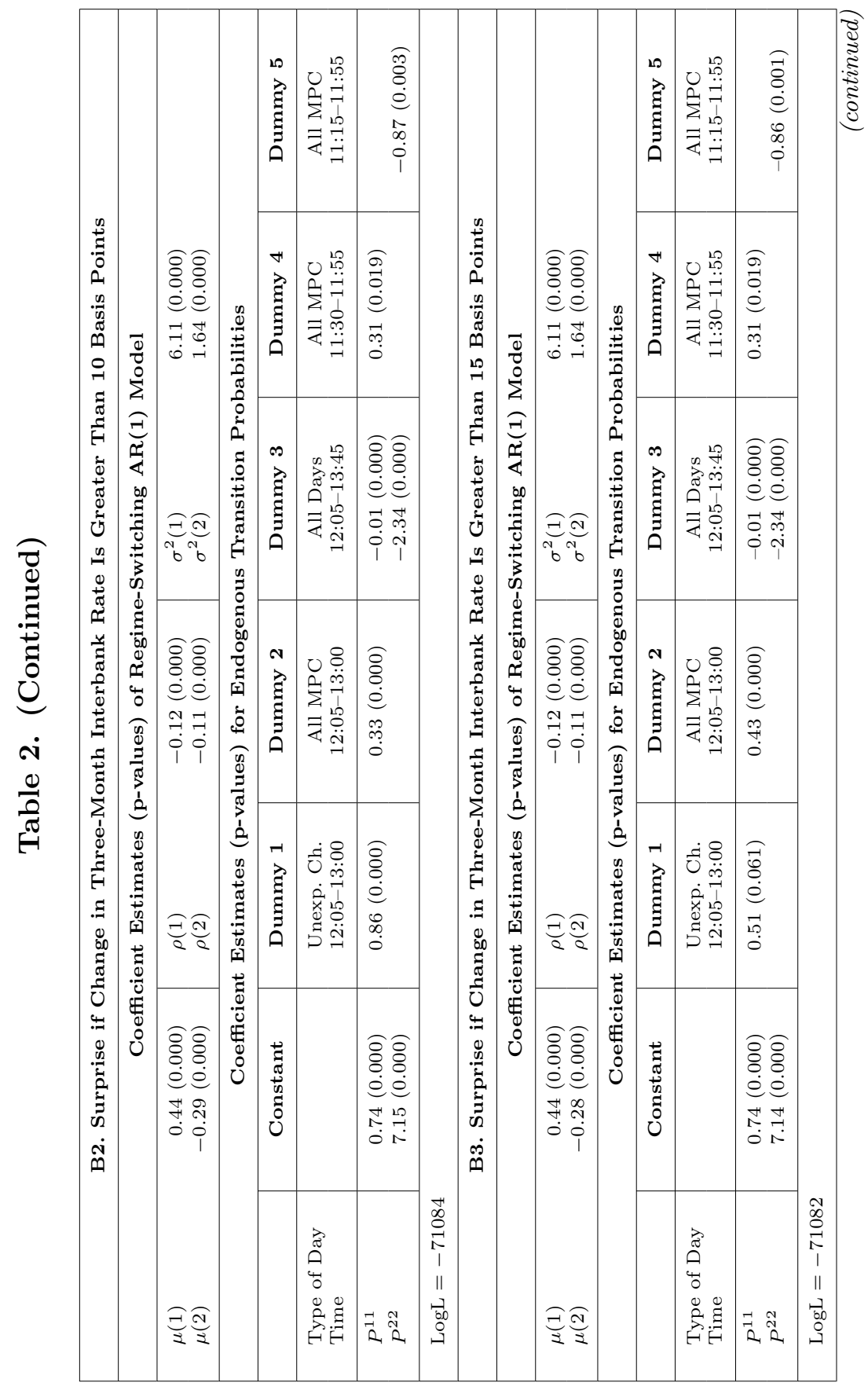




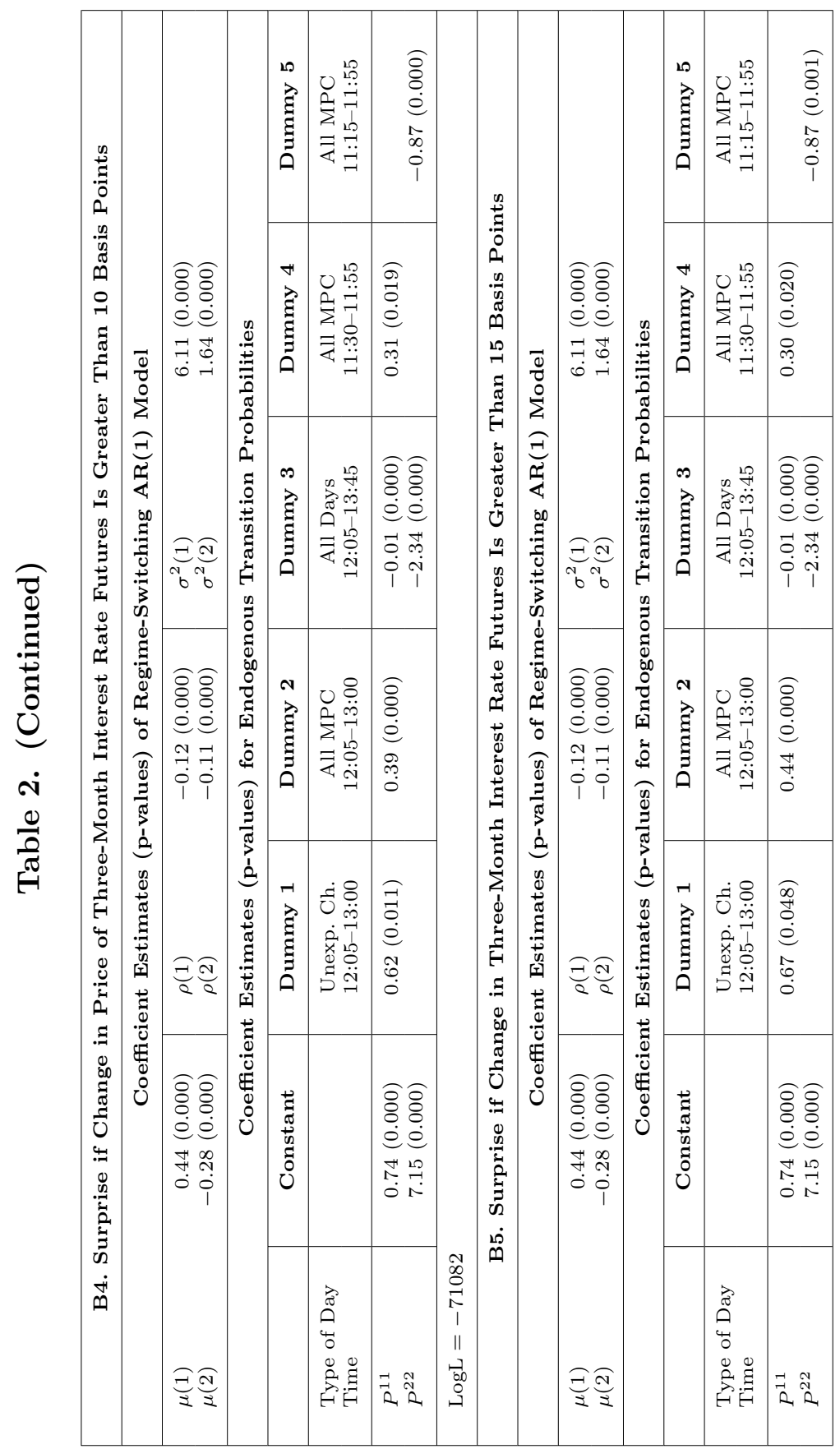


the high-volatility state and $P^{22}$ is the probability of remaining in the low-volatility state. Normally, we would expect $P^{22}>P^{11}$ and, from table 2, this is what the data reveal. Estimating a Markovswitching model with fixed transition probabilities results in the following estimates: $P^{11}=\Phi(1.68)=0.95$ and $P^{22}=\Phi(1.74)=0.96$. The unconditional probability of being in state 2 associated with these transition probabilities is given as $\frac{\left(1-P^{11}\right)}{\left(1-P^{11}\right)+\left(1-P^{22}\right)}=0.556$, and the unconditional probability of being in state 1 is 0.444 .

Moving to the time-varying probabilities model (table 2, panel $\mathrm{B})$, it is first interesting to find that the mean return is significantly positive in the high-volatility state and significantly negative in the low-volatility state. This result might appear puzzling, as it suggests that return volatility is high when the pound appreciates against the dollar and low when it depreciates. Consequently, it is interesting to investigate whether this result is driven by MPC announcements or is simply an artifact of the data in the sample period considered.

To consider this issue, we include additional intercept terms into the mean equation of our preferred specification:

$$
\begin{aligned}
\Delta e_{t}= & \mu\left(S_{t}\right)+\mu_{\text {pos }}\left(S_{t}\right) I(\Delta i>0)+\mu_{\text {neg }}\left(S_{t}\right) I(\Delta i<0) \\
& +\rho\left(S_{t}\right)\left[\Delta e_{t-1}-\mu\left(S_{t-1}\right)\right]+\varepsilon_{t},
\end{aligned}
$$

where $\mu_{\text {pos }}$ and $\mu_{n e g}$ are additional constant terms, $I(\Delta i>0)$ is an indicator function that takes the value of one on Unexpected Change days between 12:05 and 13:00 if the announced interest rate is higher than expected, and $I(\Delta i<0)$ is an indicator function that takes the value of one on Unexpected Change days between 12:05 and 13:00 if the announced interest rate is lower than expected. ${ }^{12}$

As table 3 reveals, the coefficients on $\mu_{\text {pos }}$ are significantly positive in both states and the coefficients on $\mu_{\text {neg }}$ significantly negative. These results indicate, as expected, that a higher UK policy rate than expected yields a positive mean return to holding sterling during the main impact period of the announcement, implying that the pound appreciates. A lower policy rate than expected yields a negative mean return during the main impact period of

\footnotetext{
${ }^{12}$ We select this definition for the indicator function, as our analysis below will demonstrate that the impact of interest rate announcements on the market is largest between 12:05 and 13:00 on Unexpected Change days.
} 


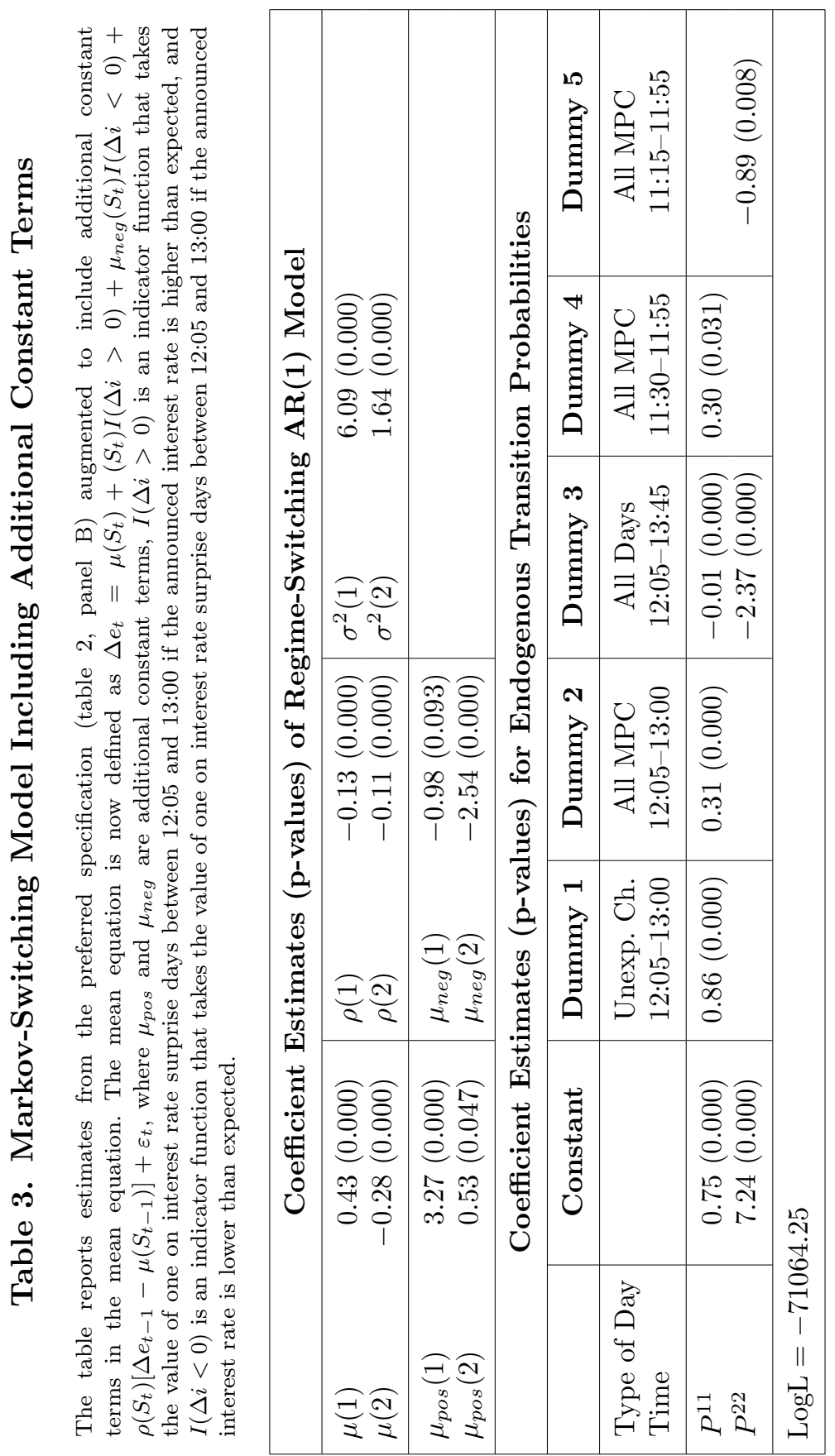


the announcement, implying that the pound depreciates. Despite inclusion of these control dummies, however, none of our previous results are changed in any significant way. This indicates that our original finding is a general characteristic of the data during our sample, rather than a function of surprise policy announcements. Periods when the pound appreciates against the dollar tend to be more volatile than periods when the pound depreciates.

Returning to the core focus of our investigation, and table 2, panel $\mathrm{B}$, transition probabilities in our preferred specification are modeled as varying with dummy variables that equal one at designated times of day and zero otherwise. Preliminary estimates suggest that the preferred model expresses $P^{11}$ as a function of a constant, a dummy equal to one from 12:05 to 13:00 only on Unexpected Change days, a dummy equal to one from 12:05 to 13:00 on All MPC days, a dummy equal to one on All days between 12:05 and 13:45, and a dummy equal to one between 11:30 and 11:55 on All MPC days. ${ }^{13}$ $P^{22}$ is a function of a constant, a dummy equal to one on All days between 12:05 and 13:45, and a dummy equal to one on All MPC meeting days from 11:15 to 11:55. All estimated coefficients differ significantly from zero with p-values of 0.02 or lower.

The results indicate that the probability of remaining in the informed trading state, $P^{11}$, is significantly higher from 12:05 to 13:00 on Unexpected Change days. This can seen in figure 2, which plots the smoothed unconditional probability of being in state 1 for the three types of days in our sample, as generated by the preferred model reported in table 2 . This probability is averaged across all observations for each type of day and for each five-minute interval.

As figure 2 highlights, there are dramatic differences across types of days and time of day. Based upon our preferred model specification, non-MPC meeting days are characterized by low-volatility, liquidity trading, as the probability of remaining in the informed trading state (that is, state 1 ) remains low throughout the day, fluctuating between 0.25 and 0.45 . On No Unexpected Change days, the average unconditional probability of being in state 1 begins to rise just before 11:30 until 12:05, when it jumps to about 0.53. After

\footnotetext{
${ }^{13}$ Notice that the observation for 12:05 on any given day is the last quotation within the interval 12:00-12:05, i.e., the first observation in our data set after the interest rate announcement.
} 


\section{Figure 2. Smoothed Unconditional Probability of Informed Trading State}

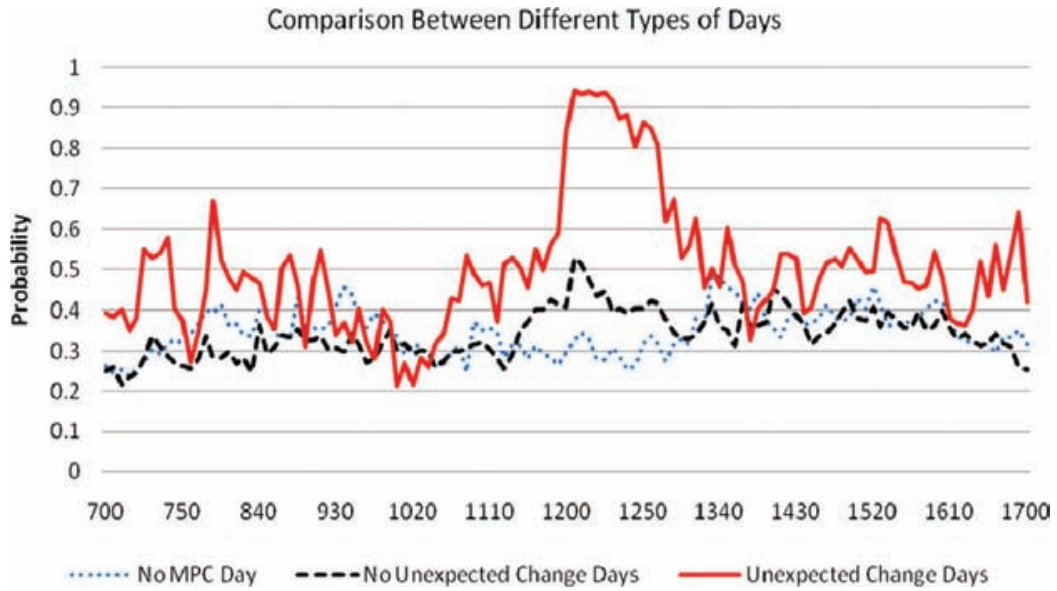

this peak, the probability quickly falls to 0.40 by $12: 30$, and then by 13:00 is quite similar to the afternoon pattern on non-MPC days.

On Unexpected Change days, however, there is a dramatic jump in the probability of being in state 1 at noon when the policy announcement is released, from about 0.55 to more than 0.90 . The probability of being in the informed trading state remains above 0.70 until about 13:00. Thereafter it falls back and, by about 13:30, follows a pattern much like other days.

The probability of remaining in the tranquil state, $P^{22}$, falls between 11:15 and 11:55 on All MPC days and between 12:05 and 13:45 on All days. Although these changes in $P^{22}$ are statistically significant, one may argue that they are not economically significant.

It is important to verify that our findings thus far are robust, and accordingly we now report and discuss a series of checks to these results.

\subsection{Alternative Measures of Market Expectations}

Thus far, we have measured market expectations using the Bloomberg survey of economists. Table 2, panels B2-B5 report estimated results for our preferred model above, albeit replacing 


\section{Figure 3. Smoothed Unconditional Probability of Informed Trading State}

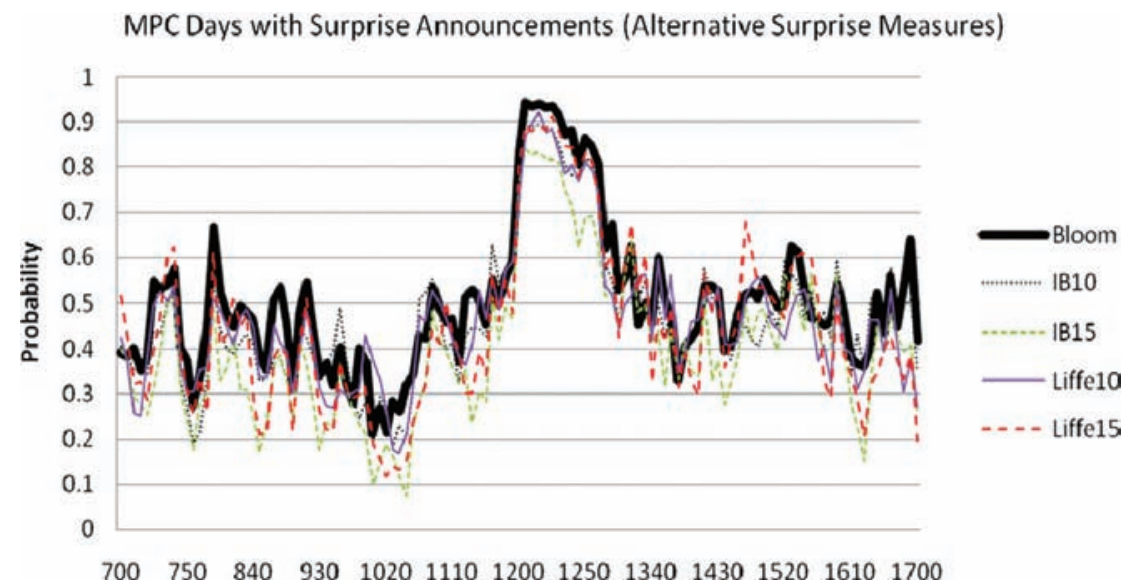

the Bloomberg measure with the alternative measures of market expectations based upon interest rates and futures, as detailed above. For each of the alternative surprise measures, the smoothed unconditional probability of being in the informed trading state on Unexpected Change days is plotted in figure 3. The similarity of the results in tables 2 and 3, and of figures 2 and 3, is striking and suggests that our findings are robust to changing the precise characterization of policy surprises. Accordingly, for the remainder of our analysis we concentrate on the Bloomberg survey surprise measure.

\subsection{Alternative Dummy Variables}

Results reported above concentrate on Unexpected Change days. In table 4, we augment our preferred model with an additional explanatory dummy variable, defined according to the same time divisions as previously, but also for No Unexpected Change days and All days. For instance, the dummy "Additional 1" is equal to one from 12:05 to 13:00 on All days. From table 4, none of the added dummy variables is statistically significant, indicating once more that our initial results are robust. 


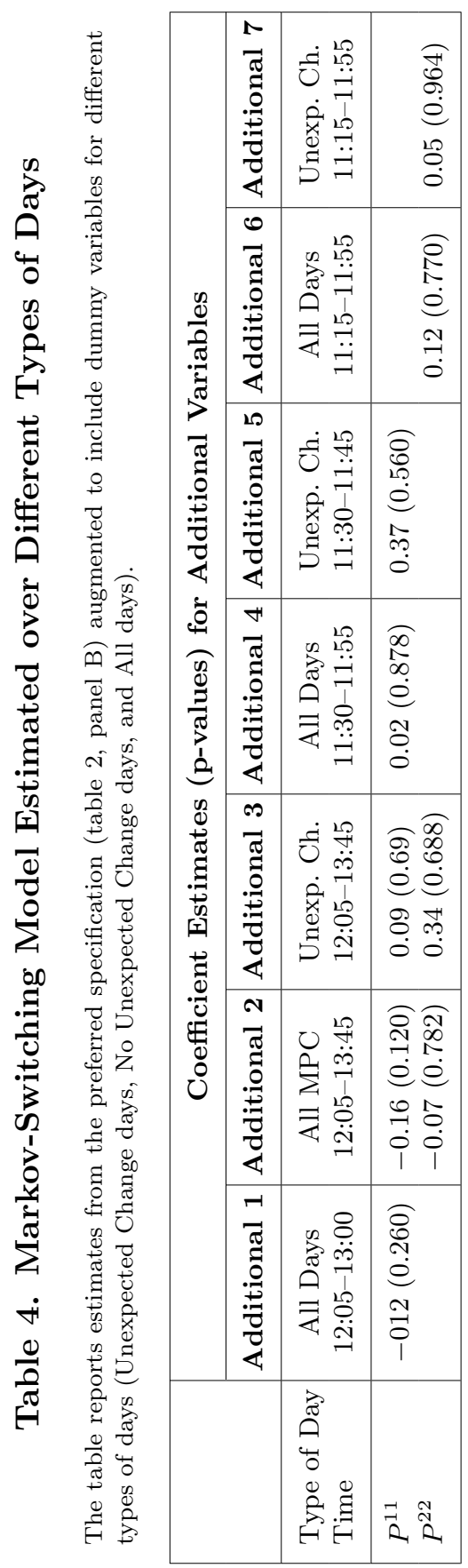




\subsection{Concurrent Central Bank Actions}

One difficulty with the analysis of macroeconomic news impacts upon exchange rates, or asset prices, is to ensure that the estimated intraday state probabilities truly reflect the impact of MPC policy announcements, rather than the effect of other news or shocks. One potential omitted variable in our analysis thus far is the announcement calendar of other central banks. In particular, there are twentyeight meetings in our sample where MPC announcement days coincide with policy announcements by the Governing Council of the European Central Bank (ECB). Announcements by the ECB occur at 12:45 GMT, which coincides with the reported significant increase in the probability of remaining in the informed trading state $P^{11}$ following MPC announcements. To test whether significant volatility shifts in dollar-sterling returns partly reflect a response to ECB interest rate decisions, we include a set of dummy variables to proxy for these announcements. This analysis is reported in table 5. Dummies take the value of one for time periods starting at 12:45 GMT on (i) all days on which MPC and ECB policy announcements coincide, (ii) those coincident days on which the ECB announced an interest rate change, or (iii) only those coincident days which involved an ECB policy surprise. ${ }^{14}$ As table 5 reports, only the dummy covering the period 12:45-17:00 on All coinciding days is significant when included in the specification for $P^{11} \cdot{ }^{15}$ But our initial results are not altered substantively by the inclusion of ECB dummy variables.

Overall, we can conclude that the evidence in tables 2-5 represents a robust set of results. We have demonstrated significant evidence of a systematic regime switch to a high-volatility, informed trading state on MPC Unexpected Change days. This effect is significant for about an hour following the interest rate announcement, before the probability of remaining in the informed trading state

\footnotetext{
${ }^{14}$ We define ECB surprise announcement days according to changes in the short-term interbank rate (EURIBOR) using the same approach as for the BoE in table 1.

${ }^{15} \mathrm{~A}$ priori, one would expect the coefficient on this dummy variable to have a positive sign, indicating that ECB policy announcements raise the probability of higher dollar-sterling return volatility. The observed negative sign may indicate, then, that this dummy is capturing something other than the volatility impact of ECB policy announcements.
} 


\section{Table 5. Concurrent Central Bank Announcements}

The table reports estimates from the preferred specification (table 2, panel B) augmented to include time dummy variables to capture days on which MPC and ECB policy announcements coincide. There are three types of coincident days: all days on which the MPC and ECB policy announcements coincide, those coincident days on which the ECB announced an interest rate change, and those coincident days on which the ECB policy announcement was unexpected by the median market expectation.

\begin{tabular}{|l|l|c|c|c|}
\hline Equation & \multicolumn{1}{c|}{ Day } & \multicolumn{1}{c|}{ Time } & $\begin{array}{c}\text { Coefficient } \\
\text { (p-value) }\end{array}$ & $\begin{array}{c}\text { Log } \\
\text { Likelihood }\end{array}$ \\
\hline$P^{11}$ & ECB Coincides & $12: 45-14: 00$ & $-0.12(0.255)$ & -71082 \\
$P^{11}$ & ECB Rate Change & $12: 45-14: 00$ & $-0.09(0.636)$ & -71082 \\
$P^{11}$ & ECB Surprise Change & $12: 45-14: 00$ & $-0.54(0.151)$ & -71081 \\
$P^{22}$ & ECB Coincides & $12: 45-14: 00$ & $-0.004(0.992)$ & -71082 \\
$P^{22}$ & ECB Rate Change & $12: 45-14: 00$ & $-0.657(0.402)$ & -71082 \\
$P^{22}$ & ECB Surprise Change & $12: 45-14: 00$ & $0.35(0.777)$ & -71082 \\
$P^{11}$ & ECB Coincides & $12: 45-17: 00$ & $-0.21(0.02)$ & -71078 \\
$P^{11}$ & ECB Rate Change & $12: 45-17: 00$ & $-0.06(0.630)$ & -71082 \\
$P^{11}$ & ECB Surprise Change & $12: 45-17: 00$ & $-0.41(0.056)$ & -71080 \\
$P^{22}$ & ECB Coincides & $12: 45-17: 00$ & $0.30(0.182)$ & -71081 \\
$P^{22}$ & ECB Rate Change & $12: 45-17: 00$ & $-0.29(0.473)$ & -71082 \\
$P^{22}$ & ECB Surprise Change & $12: 45-17: 00$ & $0.84(0.330)$ & -71082 \\
\hline
\end{tabular}

falls back to pre-announcement levels. The pattern of return volatility is clearly distinguished from other days in our sample and is not simply a "time-of-day" effect that is always present, regardless of policy announcements. These results are also robust to the inclusion of various alternative time-of-day dummies that account for concurrent actions of the ECB.

Consequently, in response to the first two questions posed above (Can we identify endogenous regime switching? Are the transition probabilities driven by the news component in the policy announcements?), we can answer with a strong affirmation.

\subsection{Pre-Announcement Positioning Effects?}

We now turn to the third question to be addressed: Is there evidence of positioning during MPC meetings prior to the policy announcement at noon on the second meeting day? 
We capture this news anticipation effect in our preferred model (table 2, panel B) by the coefficients on the dummy variable for 11:30-11:55 on All MPC days in the $P^{11}$ equation and the dummy variable for $11: 15-11: 55$ on All MPC days in the $P^{22}$ equation. Both dummy variables are significant, and the coefficients imply an increased probability of remaining in the informed trading state from 11:30 to 11:55 and a decreased probability of remaining in the normal liquidity trading state from 11:15 to 11:55.

Panels A, B, and $\mathrm{C}$ of table 6 incorporate alternative morning dummy variables into the preferred model as a further robustness check. This check proceeds much like the analysis associated with the post-announcement effect above for three different types of days: All days, All MPC days, and Unexpected Change days. For instance, the first row of table 6 , panel A includes a dummy equal to one from 11:45 to 11:55 on All days in the $P^{11}$ equation. None of the dummies for either All days or All MPC days is significant, and our preferred model results are not altered by the inclusion of these variables.

By contrast, in table 6, panel $\mathrm{C}$, dummies for the periods 11:4511:55, 11:30-11:55, and 11:00-11:55 on Unexpected Change days enter the $P^{11}$ equation with significant $\mathrm{p}$-values and positive coefficients. The dummy for 9:00-11:55 in the $P^{22}$ equation is borderline significant as well and has a negative coefficient. This suggests that the probability of being in the high-volatility state increases during the morning of Unexpected Change days, whereas it does not on days when the announcement is anticipated. In addition, the results of our preferred model specification are once again not substantively changed by the inclusion of these variables.

Taken as a whole, therefore, there is evidence that exchange rate volatility switches between low and high regimes during the morning prior to the end of MPC meetings and, in particular, prior to those meetings that eventually deliver an unexpected change in the Bank rate. The evidence is strongest for the $P^{11}$ equation for the 11:30-11:55 time period. Because the meetings always end prior to the noon announcement and the MPC's policy decision is known by insiders, this regime switching could be a result of signals read by market participants. This is not to claim that there are deliberate information leaks emanating from the Committee; it may be something much more subtle. Alternatively, it may be that traders simply close down positions during the morning in order to limit their 


\section{Table 6. Markov-Switching Model of MPC News Anticipation Effects}

The table reports estimates and tests of alternative specifications of the Markovswitching model for dollar-sterling exchange rate returns, using the model reported in table 2, panel B as the baseline model. Only the estimated coefficients (p-values) for the additional dummy in the transition probability equations are reported here.

\begin{tabular}{|c|c|c|c|}
\hline \multicolumn{4}{|c|}{$\begin{array}{l}\text { A. Alternative Specifications (Morning Dummies for All Days) } \\
\text { Additional Variables Added to the Preferred Model Specification }\end{array}$} \\
\hline Equation & Variable & $\begin{array}{l}\text { Coefficient } \\
\text { (p-value) }\end{array}$ & $\begin{array}{l}\text { Log } \\
\text { Likelihood }\end{array}$ \\
\hline$P^{11}$ & $11: 45-11: 55$ & $-0.169(0.300)$ & -71082 \\
\hline$P^{11}$ & $11: 30-11: 55$ & $-0.08(0.564)$ & -71082 \\
\hline$P^{11}$ & $11: 15-11: 55$ & $-0.07(0.500)$ & -71082 \\
\hline$P^{11}$ & $11: 00-11: 55$ & $-0.000(0.999)$ & -71082 \\
\hline$P^{11}$ & $9: 00-11: 55$ & $-0.000(0.999)$ & -71082 \\
\hline$P^{22}$ & $11: 45-11: 55$ & $0.10(0.862)$ & -71082 \\
\hline$P^{22}$ & $11: 30-11: 55$ & $0.32(0.459)$ & -71082 \\
\hline$P^{22}$ & $11: 15-11: 55$ & $0.12(0.769)$ & -71082 \\
\hline$P^{22}$ & $11: 00-11: 55$ & $0.000(0.999)$ & -71082 \\
\hline$P^{22}$ & 9:00-11:55 & $0.000(0.999)$ & -71082 \\
\hline \multicolumn{4}{|c|}{$\begin{array}{l}\text { B. Alternative Specifications (Morning Dummies for All MPC Days) } \\
\text { Additional Variables Added to the Preferred Model Specification }\end{array}$} \\
\hline$P^{11}$ & $11: 45-11: 55$ & $-0.02(0.933)$ & -71082 \\
\hline$P^{11}$ & $11: 15-11: 55$ & $-0.03(0.879)$ & -71082 \\
\hline$P^{11}$ & $11: 00-11: 55$ & $0.01(0.930)$ & -71082 \\
\hline$P^{11}$ & $9: 00-11: 55$ & $0.04(0.530)$ & -71082 \\
\hline$P^{22}$ & $11: 45-11: 55$ & $-0.44(0.51)$ & -71082 \\
\hline$P^{22}$ & $11: 30-11: 55$ & $0.53(0.445)$ & -71082 \\
\hline$P^{22}$ & 11:00-11:55 & $0.66(0.291)$ & -71082 \\
\hline$P^{22}$ & $9: 00-11: 55$ & $0.18(0.460)$ & -71082 \\
\hline \multicolumn{4}{|c|}{$\begin{array}{l}\text { C. Alternative Specifications } \\
\text { (Morning Dummies for Unexpected Change Days) } \\
\text { onal Variables Added to the Preferred Model Specification }\end{array}$} \\
\hline$P^{11}$ & $11: 45-11: 55$ & $0.27(0.047)$ & -71080 \\
\hline$P^{11}$ & $11: 30-11: 55$ & $0.65(0.038)$ & -71080 \\
\hline$P^{11}$ & $11: 00-11: 55$ & $0.93(0.041)$ & -71079 \\
\hline$P^{11}$ & $11: 00-11: 15$ & $1.051(0.161)$ & -71082 \\
\hline$P^{11}$ & 9:00-11:55 & $4.65(0.953)$ & -71082 \\
\hline$P^{22}$ & $11: 45-11: 55$ & $-0.28(0.552)$ & -71082 \\
\hline$P^{22}$ & $11: 30-11: 55$ & $-0.07(0.935)$ & -71082 \\
\hline$P^{22}$ & $11: 15-11: 55$ & $0.05(0.964)$ & -71082 \\
\hline$P^{22}$ & 11:00-11:55 & $0.28(0.828)$ & -71082 \\
\hline$P^{22}$ & $9: 00-11: 55$ & $-1.88(0.056)$ & -71082 \\
\hline
\end{tabular}


risk exposure precisely because they are unsure about the upcoming policy announcement. Furthermore, the evidence presented here indicates no particularly large probability shifts prior to the conclusion of MPC meetings, especially when compared with the afternoon of Unexpected Change days. Consequently, the news impact of policy announcements appears to be much larger than any anticipation effect.

\subsection{Dispersion of Market Expectations}

An interesting feature of figure 2 is that the probability of moving into the high-volatility state rises even on No Unexpected Change days. This is worthy of further investigation, as one might expect anticipated announcements to be discounted into the exchange rate in advance. One explanation may be our use of median Bloomberg survey expectations with no regard for any dispersion in expectations among survey participants. There will in general be some people surveyed who are surprised by the announcement even when it coincides with the median view. If these people then react to the announcement, this may generate a series of "hot-potato" trades, although the multiplier effect is likely to be smaller than if a majority of the market is surprised.

In order to investigate the validity of this argument, we use the measure of forecast dispersion introduced in table 1 to distinguish MPC days when analysts were unanimous on the expected policy announcement from days when they were not. We construct a dummy that takes a value of one from 12:05 to 13:00 on No Unexpected Change days when the standard deviation of analysts' expectations is zero, and another that takes the value of one from 12:05 to 13:00 on No Unexpected Change days when the standard deviation is greater than zero. We include both of these variables in the $P^{11}$ equation of our preferred specification and exclude "Dummy 2" from the original specification; recall from table 2, panel B that dummy 2 takes a value of one during the period 12:05-13:00 on All MPC days. The data set is reduced to 24,683 observations due to a lack of data on analysts' expectations prior to October 1998.

Results are reported in table 7 . Only the dummy variable equal to one on No Unexpected Change days with dispersion in expectations exerts a significant influence on $P^{11}$, with a p-value of 0.001 and a coefficient of 0.4 . This suggests that the rise in $P^{11}$ at noon on 


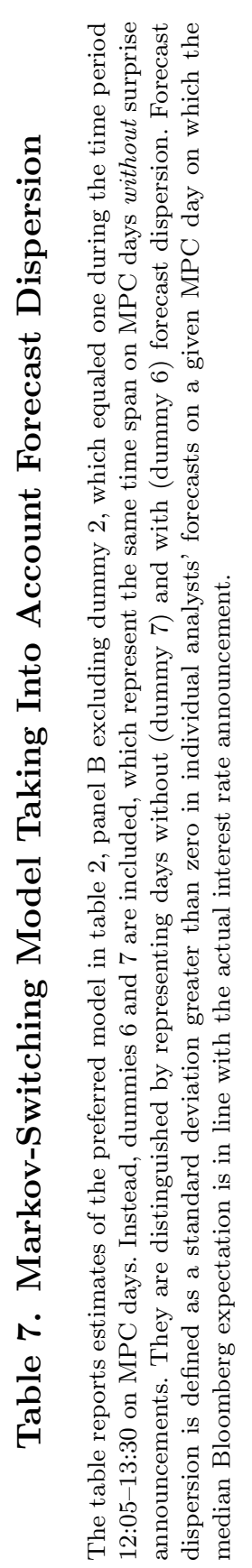

\begin{tabular}{|c|c|c|c|c|c|c|c|c|}
\hline \multirow{7}{*}{ 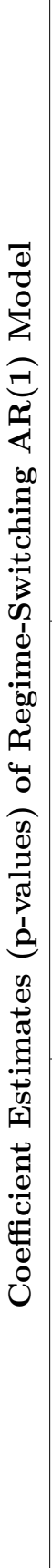 } & & 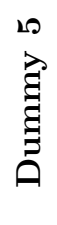 & 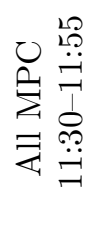 & 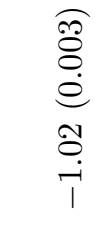 & & & & \\
\hline & 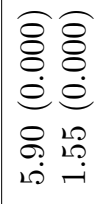 & $\begin{array}{l}\vec{H} \\
\stackrel{\vec{\Xi}}{\Xi} \\
\stackrel{\Xi}{\Xi}\end{array}$ & 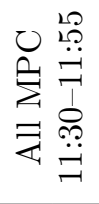 & 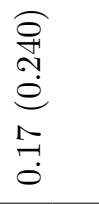 & & & & \\
\hline & 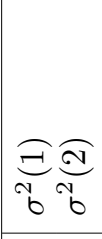 & 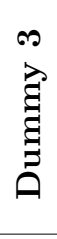 & 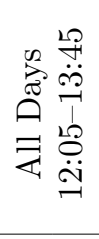 & 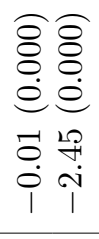 & & & & \\
\hline & $\begin{array}{ll}2 & 0 \\
8 & 8 \\
0 & 0 \\
\dot{0} & 0 \\
m & \ddots \\
ت & 7 \\
\dot{0} & \dot{0} \\
1 & 1\end{array}$ & 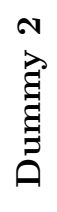 & 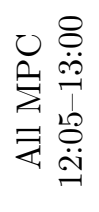 & 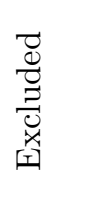 & & & & \\
\hline & 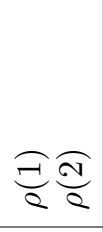 & 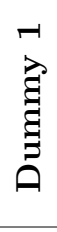 & 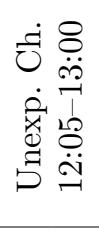 & 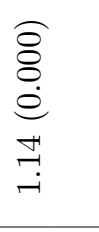 & 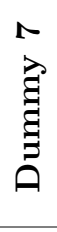 & 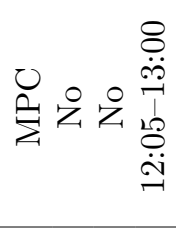 & 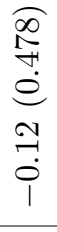 & \\
\hline & 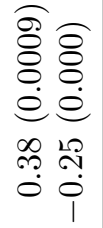 & 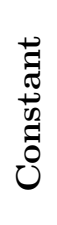 & & 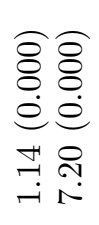 & 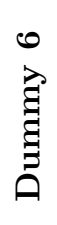 & 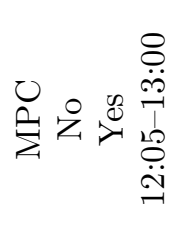 & $\begin{array}{l}\widehat{\widehat{\Xi}} \\
\stackrel{0}{0} \\
0 \\
\stackrel{0}{0} \\
\dot{0}\end{array}$ & \\
\hline & 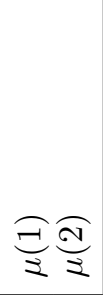 & & 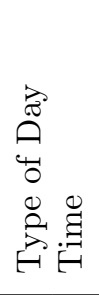 & $\overrightarrow{\vec{R}}, \tilde{N}$ & 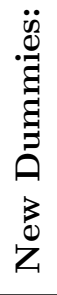 & 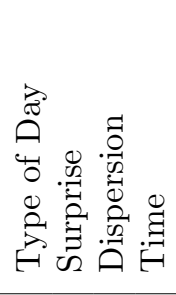 & $\vec{R}$ & 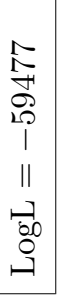 \\
\hline
\end{tabular}


No Unexpected Change days is indeed significant only when at least one individual deviates from the median market expectation. This validates the argument above that our use of the median individual analyst's expectation as a proxy for the entire market's expectation explains why apparently anticipated policy actions always impact the probability of being in the high-volatility state.

Overall, the evidence in figure 2 indicates that MPC days are different from other days. The noon policy announcement appears to be price-relevant news - in particular, when the announcement comes as a surprise to the market. There is some modest evidence of positioning in advance of the announcement on all MPC days, but for days when interest rates are changed unexpectedly, it appears that the largest market response comes immediately at noon with the news. It also appears that the market takes around an hour to digest the news component of an unanticipated announcement.

It is interesting to contrast our results with those of Evans and Lyons (2007). We conclude in favor of a significant but relatively short-lived news impact upon the volatility of exchange rate returns from interest rate announcements. By contrast, Evans and Lyons' analysis of proprietary order flow data concludes in favor of a very persistent relationship between order flow and exchange rate returns, with the former exhibiting out-of-sample predictive power for returns as much as one quarter ahead but no significant impact in the short term. This contrast appears to reflect differences in the behavior of market participants in the various segments of the foreign exchange market. In this paper, we have isolated the impact of knee-jerk trading on the volatility of returns around the time of MPC interest rate announcements, as interdealer positioning adjusts to reflect the arrival of this new information. This is an important and quick process, as befits a market as liquid and relatively efficient as foreign exchange. But it is only part of the story. Evans and Lyons (2007) focus explicitly away from interdealers and on the customer segment of the market that accounts for more than 50 percent of market turnover. ${ }^{16,17}$ As Sager and Taylor (2006) discuss, other than

\footnotetext{
${ }^{16}$ For information on the share in foreign exchange market turnover of the various market segments, see Bank for International Settlements (2007).

${ }^{17}$ This segment includes asset management firms, hedge funds, corporations, and central banks.
} 
smaller hedge funds, the majority of foreign exchange market customers typically do not exhibit knee-jerk reaction to news in the same way as the interdealer market. Although this behavior contradicts the rational-expectations hypothesis, it is rational-in the sense of being profit maximizing - and reflects both the size of assets under management, and associated transaction costs of trading, and that a large proportion of the trading activity of this market segment is not driven by news innovations, but rather by benchmark adjustments (Lyons 2001).

\section{Conclusion}

The Bank of England Monetary Policy Committee, created in 1997, was charged with implementing monetary policy consistent with stable inflation and economic growth. A stated aim of the new regime was that monetary policy should be more transparent than hitherto (King 2000).

Because the MPC meets at regularly scheduled, pre-announced times and the policy decision is always announced at noon on the second meeting day, it provides a rare opportunity to examine how the decisions of a key policy-setting committee are impounded into the foreign exchange market. Our particular interest is with respect to the news content of the policy announcement and also whether there is evidence of market positioning during meetings but prior to announcements.

We examined MPC policy announcement days using five-minute exchange rate returns and a Markov-switching framework. Our estimated model assumed the existence of a high-volatility state associated with informed trading and a low-volatility state associated with liquidity trading. We diverged from the usual non-linear regimeswitching framework to model endogenous transition probabilities as a function of information regarding the meeting days. The transition probabilities were found to switch systematically and significantly on meeting days. In particular, the probability of remaining in the high-volatility state was estimated to increase significantly on MPC meeting days when interest rates were changed by an amount different from the ex ante median market expectation, or were not changed when the market expected a change. 
The announcement day of MPC meetings can therefore be characterized as having a statistically and economically significant exchange rate reaction to the MPC news announcement at noon, with some evidence of pre-positioning during the morning of the meeting. These results are qualitatively similar to those reported by Sager and Taylor (2004) in their high-frequency study of the exchange rate effects of ECB interest rate announcements, suggesting that they are robust. ${ }^{18}$

An interesting extension of our results would be to empirically test the ability of market participants to profitably exploit these announcement effects - that is, to validate the economic significance of our findings - through a profit-loss analysis of trading strategies that, say, introduce short-lived option structures in dollar-sterling on the second day of MPC meetings around the time of the policy announcement. This is a task we leave to future research.

\section{References}

Ahn, S. C., and M. Melvin. 2007. "Exchange Rates and FOMC Days." Journal of Money, Credit, and Banking 39 (5): 1245-66. Almeida, A., C. A. E. Goodhart, and R. Payne. 1998. "The Effects of Macroeconomic News on High Frequency Exchange Rate Behavior." Journal of Financial and Quantitative Analysis 33 (3): 383408.

Andersen, T. G., and T. Bollerslev. 1998. "Deutsche MarkDollar Volatility: Intraday Activity Patterns, Macroeconomic Announcements, and Longer Run Dependencies." Journal of Finance 53 (1): 219-65.

Andersen, T. G., T. Bollerslev, F. X. Diebold, and C. Vega. 2003. "Micro Effects of Macro Announcements: Real-Time Price Discovery in Foreign Exchange." American Economic Review 93 (1): $38-62$.

Bank for International Settlements. 2007. "Triennial Central Bank Survey of Foreign Exchange and Derivatives Market Activity in

\footnotetext{
${ }^{18}$ Likewise, Clare and Courtenay (2001) find in favor of a significant impact on exchange and interest rate volatility from UK monetary policy announcements and macroeconomic data releases using one-minute tick data. They also find that news effects have become more short lived since the BoE was granted operational independence.
} 
2007 - Final Results." Press Release, December 19. Available at www.bis.org/press/p071219.htm.

Bean, C. 2001. "The Formulation of Monetary Policy at the Bank of England." Quarterly Bulletin (Bank of England) Winter: 434-41. Clare, A., and R. Courtenay. 2001. "Assessing the Impact of Macroeconomic News Announcements on Securities Prices under Different Monetary Policy Regimes." Bank of England Working Paper No. 125.

Danielsson, J., and R. Payne 2002. "Real Trading Patterns and Prices in Spot Foreign Exchange Markets." Journal of International Money and Finance 21 (2): 203-22.

Diebold, F., J. H. Lee, and G. C. Weinbach. 1994. "Regime Switching with Time-Varying Transition Probabilities." In Nonstationary Time Series Analysis and Cointegration, ed. C. P. Hargreaves, 283-302. Oxford and New York: Oxford University Press.

Easley, D., and M. O'Hara. 1992. "Time and the Process of Security Price Adjustment." Journal of Finance 49 (2): 577-606.

Ederington, L. H., and J. H. Lee. 1993. "How Markets Process Information: News Releases and Volatility." Journal of Finance 48 (4): $1161-91$.

. 1995. "The Short-Run Dynamics of the Price Adjustment to New Information." Journal of Financial and Quantitative Analysis 30 (1): 117-34.

- 1996. "The Creation and Resolution of Market Uncertainty: The Impact of Information Releases on Implied Volatility." Journal of Financial and Quantitative Analysis 31 (4): 513-39.

Engel, C., and J. D. Hamilton. 1990. "Long Swings in the Dollar: Are They in the Data and Do Markets Know It?" American Economic Review 80 (4): 689-713.

Evans, M. D. D., and R. K. Lyons. 2007. "Exchange Rate Fundamentals and Order Flow." NBER Working Paper No. 13151.

Faust, J., J. H. Rogers, E. Swanson, and J. H. Wright. 2003. "Identifying the Effects of Monetary Policy Shocks on Exchange Rates Using High Frequency Data." Journal of the European Economic Association 1 (5): 1031-57.

Goodhart, C. A. E., S. G. Hall, S. G. B. Henry, and B. Pesaran. 1993. "News Effects in a High-Frequency Model of the Sterling-Dollar Exchange Rate." Journal of Applied Econometrics 8 (1): 1-13. 
Hakkio, C. S., and D. K. Pearce. 1985. "Exchange Rates and Discount Rate Changes." Federal Reserve Bank of Kansas City Research Working Paper No. 86-06.

Hamilton, J. D. 1990. "Analysis of Time Series Subject to Changes in Regime." Journal of Econometrics 45 (1-2): 39-70.

. 1994. Time Series Analysis. Princeton, NJ: Princeton University Press.

Harvey, C. R., and R. D. Huang. 2002. "The Impact of the Federal Reserve Bank's Open Market Operations." Journal of Financial Markets 5 (2): 223-57.

Ito, T., and V. V. Roley. 1987. "News from the U.S. and Japan: Which Moves the Yen/Dollar Exchange Rate?" Journal of Monetary Economics 19 (2): 255-77.

King, M. 2000. "Monetary Policy: Theory and Practice." Address to the joint luncheon of the American Economic Association and the American Finance Association, Boston, Massachusetts, January 7. Available at www.bankofengland.co.uk/publications/ speeches $/ 2000 /$ speech67.htm.

Lyons, R. K. 1996. "Foreign Exchange Volume: Sound and Fury Signifying Nothing?" In The Microstructure of Foreign Exchange Markets, ed. J. A. Frankel, G. Galli, and A. Giovannini, 183-201. Chicago: Chicago University Press for NBER.

- 2001. The Microstructure Approach to Exchange Rates. Cambridge, MA and London: MIT Press.

Sager, M., and M. P. Taylor. 2004. "The Impact of European Central Bank Governing Council Announcements on the Foreign Exchange Market: A Microstructural Analysis." Journal of International Money and Finance 23 (7-8): 1043-51.

. 2006. "Under the Microscope: The Structure of the Foreign Exchange Market." International Journal of Finance and Economics 11 (1): 81-95.

Taylor, M. P. 1987. "Covered Interest Parity: A High-Frequency, High-Quality Data Study." Economica 54 (216): 429-38.

- 1989. "Covered Interest Arbitrage and Market Turbulence." Economic Journal 99 (396): 376-91. 